\begin{tabular}{|c|c|c|c|}
\hline $\begin{array}{l}\text { Stat4 } \\
\text { JAN } 252000\end{array}$ & ENGINEERING DATA TRANSMITTAL & 1. EDT & $6: 28130$ \\
\hline
\end{tabular}

\begin{tabular}{|c|c|c|c|c|c|c|c|c|}
\hline \multicolumn{3}{|c|}{$\begin{array}{l}\text { 2. To: (Receiving Organization) } \\
\text { Distribution }\end{array}$} & \multicolumn{2}{|c|}{$\begin{array}{l}\text { 3. From: (Originating Organization) } \\
\text { Nuclear Safety }\end{array}$} & \multicolumn{4}{|c|}{$\begin{array}{l}\text { 4. Related EDT No.: } \\
\qquad \text { N/A }\end{array}$} \\
\hline \multicolumn{3}{|c|}{$\begin{array}{l}\text { 5. Proj/Prog/Dept/Div.: } \\
\text { Spent Nuclear Fuel }\end{array}$} & \multicolumn{2}{|c|}{$\begin{array}{l}\text { 6. Design Authority/ Design Agen//Cog. Engr.: } \\
\text { M. G. Piepho, 376-8009, R3-26 }\end{array}$} & \multicolumn{4}{|c|}{$\begin{array}{r}\text { 7. Purchase Order No.: } \\
\text { N/A }\end{array}$} \\
\hline \multicolumn{5}{|c|}{ 8. Originator Remarks: } & \multicolumn{4}{|c|}{$\begin{array}{r}\text { 9. Equip./Component No.: } \\
\text { N/A }\end{array}$} \\
\hline \multicolumn{5}{|c|}{ For approval and release. } & \multicolumn{4}{|c|}{$\begin{array}{r}\text { 10. System/Bldg./Facility: } \\
\text { N/A }\end{array}$} \\
\hline \multirow{3}{*}{\multicolumn{3}{|c|}{ 11. Receiver Remarks: }} & \multirow{3}{*}{\multicolumn{2}{|c|}{ Document? [] Yes $[x]$ No }} & \multicolumn{4}{|c|}{$\begin{array}{l}\text { 12. Major Assm. Dwg. No.: } \\
\text { N/A }\end{array}$} \\
\hline & & & & & \multicolumn{4}{|c|}{ 13. Permit/Permit Application No.: } \\
\hline & & & & & \multicolumn{4}{|c|}{$\begin{array}{l}\text { 14. Required Response Date: } \\
\text { N/A }\end{array}$} \\
\hline 15. & & DAT & TRANSMI & & (F) & (G) & $(\mathrm{H})$ & (I) \\
\hline $\begin{array}{l}(A) \\
\text { them } \\
\text { No. }\end{array}$ & (B) Documentīraxing №. & $\begin{array}{l}\text { (C) } \\
\text { Sheet } \\
\text { No. }\end{array}$ & $\begin{array}{l}\text { (D) } \\
\text { Rev. } \\
\text { No. }\end{array}$ & (E) Title or Description of Dat Tansmitted & $\begin{array}{l}\text { Approval } \\
\text { Designertor }\end{array}$ & $\begin{array}{l}\text { Recson } \\
\text { for Trens- } \\
\text { mittal }\end{array}$ & $\begin{array}{l}\text { Origi- } \\
\text { nator } \\
\text { Dispo- } \\
\text { sition }\end{array}$ & $\begin{array}{c}\text { Receiver } \\
\text { Disposition }\end{array}$ \\
\hline 1 & SNF-5698 & N/A & 0 & $\begin{array}{l}\text { Comparison of Calculational } \\
\text { Results from Different Spent } \\
\text { Nuclear Fuel Crumbling } \\
\text { Approaches }\end{array}$ & $\mathrm{S}$ & 1,2 & 1 & 1 \\
\hline & & & & & & & & \\
\hline & & & & & & & & \\
\hline & & & & & & & & \\
\hline & & & & & & & & \\
\hline & & & & & & & & \\
\hline
\end{tabular}

\begin{tabular}{|c|c|c|c|c|c|c|c|c|}
\hline \multicolumn{9}{|c|}{ KEY } \\
\hline \multicolumn{3}{|c|}{ Approval Designator (F) } & \multicolumn{3}{|c|}{ Reason for Transmittal (G) } & \multicolumn{3}{|c|}{ Disposition $(H) \&(1)$} \\
\hline \multicolumn{3}{|c|}{$\begin{array}{l}\text { E,S, Q, D CrN/A } \\
(\text { see WHC-CM-3-5, Sec. } 12.7)\end{array}$} & $\begin{array}{l}\text { 1. Approval } \\
\text { 2. Relesese } \\
\text { 3. Infomation }\end{array}$ & \multicolumn{2}{|l|}{$\begin{array}{l}\text { 4. Review } \\
\text { 5. Post-Review } \\
\text { 6. Dist. (Roseipt Acknow. Required) }\end{array}$} & \multicolumn{3}{|c|}{ 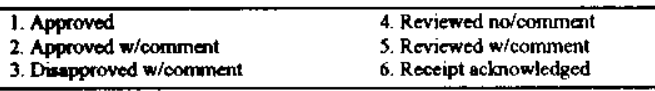 } \\
\hline \multicolumn{9}{|c|}{$\begin{array}{l}\text { 17. SIGNATUREOISTRIBUTHON } \\
\text { (SSee Approval Designator for required signatures) }\end{array}$} \\
\hline $\begin{array}{c}\text { (G) } \\
\text { Reason }\end{array}$ & $\begin{array}{c}\text { (H) } \\
\text { Disp. }\end{array}$ & & (J) Name $\quad$ (K) & aure (L) Date (M) MSIN & $\begin{array}{c}\text { (G) } \\
\text { Renson }\end{array}$ & $\begin{array}{c}\text { (H) } \\
\text { Dhisp. }\end{array}$ & (J) Name & (K) Signature (L) Date (M) MSIN \\
\hline \multirow[t]{2}{*}{1} & & Desig & thority $N A$ & & & & & \\
\hline & & Desig & ent $\quad N A$ & & & & & \\
\hline 1 & I & $\operatorname{Cog} \mathrm{E}$ & M. G. Piepho & 8 & & & & \\
\hline 1 & 1 & $\operatorname{Cog} .1$ & R. L. Garrett & $17 K=1 / 25100$ & & & & \\
\hline 1 & & & $N A$ & & & & & \\
\hline 1 & T & Safety & R. Brehm & in RTuchn 1/25 & & & & \\
\hline 3 & & Ops. & $A$ & & & & & \\
\hline
\end{tabular}
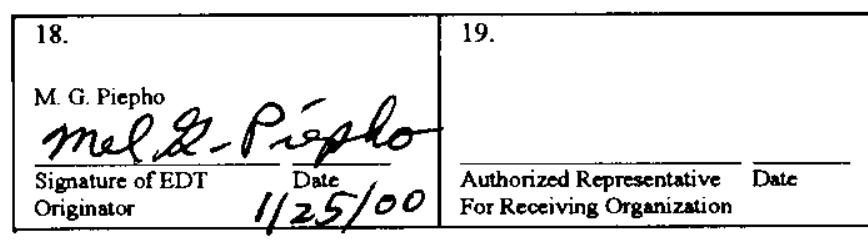

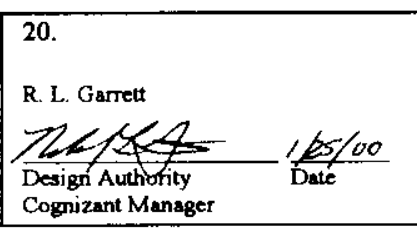

21. DOE APPROVAI, (if required)

Ctrl. No.

[] Approved

[] Approved w/comments

[ ] Disapproved w/comments 
DISTRIBUTION SHEET

\begin{tabular}{|c|c|c|c|c|c|}
\hline \multirow{2}{*}{$\begin{array}{l}\text { To } \\
\text { Distribution }\end{array}$} & \multirow{2}{*}{\multicolumn{3}{|c|}{$\begin{array}{l}\text { From } \\
\text { M. G. Piepho, Nuclear Safety }\end{array}$}} & \multicolumn{2}{|l|}{ Page 1 of 1} \\
\hline & & & & \multicolumn{2}{|l|}{ Date $1 / 25 / 00$} \\
\hline \multicolumn{4}{|l|}{ Project Title/Work Order } & \multicolumn{2}{|c|}{ EDT No. 628130} \\
\hline \multicolumn{4}{|c|}{$\begin{array}{l}\text { SNF-5698, Rev. } 0 \\
\text { Comparison of Calculational Results from Different Spent Nuclear Fuel } \\
\text { Crumbling Approaches }\end{array}$} & \multicolumn{2}{|l|}{ ECN No. N/A } \\
\hline Name & MSIN & $\begin{array}{l}\text { Text } \\
\text { With All } \\
\text { Attach. }\end{array}$ & Text Only & $\begin{array}{l}\text { Attach./ } \\
\text { Appendix } \\
\text { Only }\end{array}$ & $\begin{array}{c}\text { EDT/ECN } \\
\text { Only }\end{array}$ \\
\hline R. L. Boyleston & R3-26 & $\mathrm{x}$ & & & \\
\hline J. R. Brehm & R3-26 & $\mathrm{x}$ & & & \\
\hline B. J. Craig & R3-26 & $\mathrm{X}$ & & & \\
\hline R. D. Crowe & R3-26 & $\mathrm{X}$ & & & \\
\hline D. R. Duncan & R3-86 & $\mathrm{X}$ & & & \\
\hline J. R. Frederickson & R3-86 & $\mathrm{X}$ & & & \\
\hline R. L. Garrett & R3-26 & $\mathrm{x}$ & & & \\
\hline L. J. Garvin & R3-26 & $\mathrm{X}$ & & & \\
\hline K. D. Gibson & R3-26 & $\mathrm{X}$ & & & \\
\hline L. II. Goldman & R3-86 & $\mathrm{x}$ & & & \\
\hline B. E. Hey & $B 4-47$ & $\mathrm{x}$ & & & \\
\hline J. J. Irwin & R3-86 & $\mathrm{X}$ & & & \\
\hline D. S. Leach & B4-45 & $\mathrm{X}$ & & & \\
\hline B. D. Lorenz & R3-26 & $\mathrm{x}$ & & & \\
\hline B. J. Makenas & $\mathrm{H} 0-40$ & $\mathrm{x}$ & & & \\
\hline M. A. Medsket & R3-26 & $\mathrm{x}$ & & & \\
\hline W. C. Miller & R3-11 & $\mathrm{x}$ & & & \\
\hline C. R. Miska & R3-86 & $\mathrm{x}$ & & & \\
\hline A. L. Pajunen & R3-86 & $\mathrm{x}$ & & & \\
\hline M. G. Piepho (5) & R3-26 & $\mathrm{x}$ & & & \\
\hline R. A. Sexton & R3-86 & $\mathrm{x}$ & & & \\
\hline J. A. Swenson & R3-11 & $\mathrm{x}$ & & & \\
\hline D. J. Trimble & $\mathrm{H} 0-40$ & $\mathrm{x}$ & & & \\
\hline M. J. Wiemers & R3-11 & $\mathrm{x}$ & & & \\
\hline Central Files & B1-07 & $\mathrm{X}$ & & & \\
\hline SNF Project Files & R3-11 & $\mathrm{X}$ & & & \\
\hline Offsite & & & & & \\
\hline $\begin{array}{l}\text { M. G. Plys } \\
\text { Fauske \& Associates, Inc. } \\
162070 \text { W. } 83^{\text {rd }} \text { St. } \\
\text { Burr Ridge, IL } 60521\end{array}$ & & $\mathrm{x}$ & & & \\
\hline $\begin{array}{l}\text { S. J. Lee } \\
\text { Fauske \& Associates, Inc. } \\
284 \text { River Street } \\
\text { Troy, NY } 12180\end{array}$ & & $x$ & & & \\
\hline
\end{tabular}




\section{Comparison of Calculational Results from Different Spent Nuclear Fuel Crumbling Approaches}

M. G. Piepho

Fluor Federal Services, Richland, WA 99352

U.S. Department of Energy Contract DE-AC06-96RL13200

EDT: 628130

Org Code: 2 F200

B\&R Code: EW31354040

Charge Code: $105530 / \mathrm{CB80}$

Total Pages: 67 (JKB 1/25/00)

Key Words: Spent Nuclear Fuel, fuel crumbling, thermal runaway, TGA, Oxidation, reaction rate

Abstract: Several safety basis cases or scenarios using three different fuel crumbling or degradation approaches were simulated with a modified HANSF Code. Results of simulations are compared and discussed. The conclusion is that the safety basis fuel reaction enhancement factors are conservative and bound other fuel crumbling approaches for the results of interest.

TRADEMARK DISCLAIMER. Reference herein to any specific commercial product, process, or service by trade name, trademark, manufacturer, or otherwise, does not necessarily constitute or imply its endorsement, recommendation, or favoring by the United States Government or any agency thereof or its contractors or subcontractors.

Printed in the United States of America. To obtain copies of this document, contact: Document Control Services, P.O. Box 950, Mailstop H6-08, Richland WA 99352, Phone (509) 372-2420; Fax (509) 376-4989.
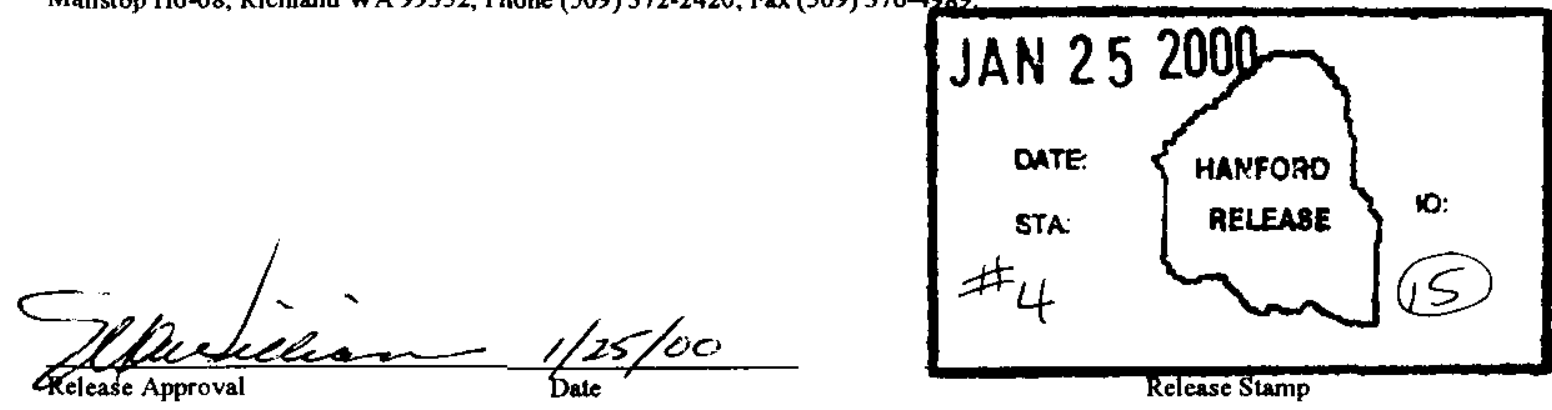

\section{Approved for Public Release}




\section{COMPARISON OF CALCULATIONAL RESULTS FROM DIFFERENT SPENT NUCLEAR FUEL CRUMBLING APPROACHES}

M. G. Piepho

Fluor Federal Service, Inc.

Richland, Washington

January 2000 
SNF-5698 REV 0

This page intentionally left blank. 


\section{CONTENTS}

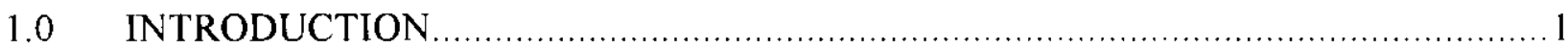

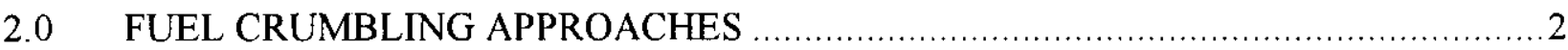

2.1 TECHNICAL ASSISTANCE GROUP FUEL CRUMBLING MODEL ...............3

2.2 CALIBRATED TECHNICAL ASSISTANCE GROUP FUEL CRUMBLING

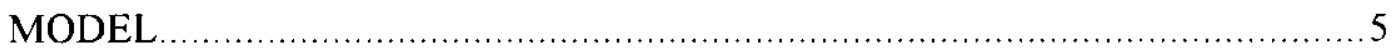

2.3 SAFETY-BASIS FUEL REACTION ENHANCEMENT FACTORS _................5

3.0 NORMAL CASES …

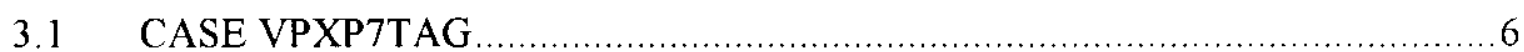

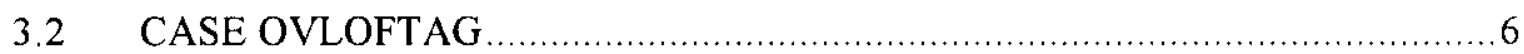

4.0 ACCIDENT CASES ……

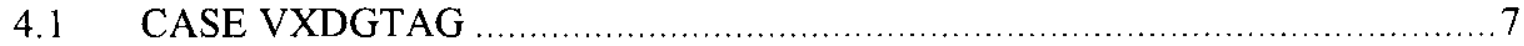

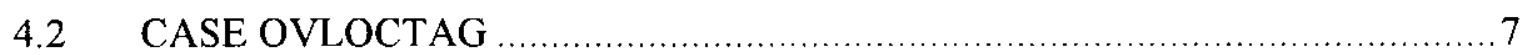

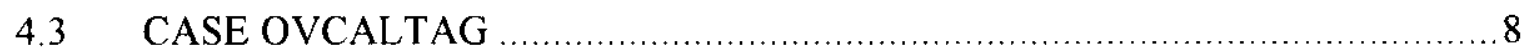

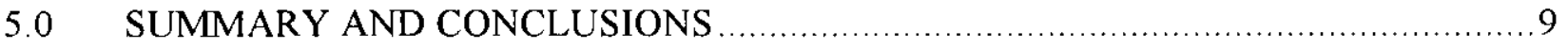

6.0 REFERENCES

\section{APPENDICES}

APPENDIX A Derivation of Technical Assistance Group Growth Rate of Area

Due to Fuel Crumbling A-1

APPENDIX B Code Changes to HANSF for Technical Assistance Group Fuel

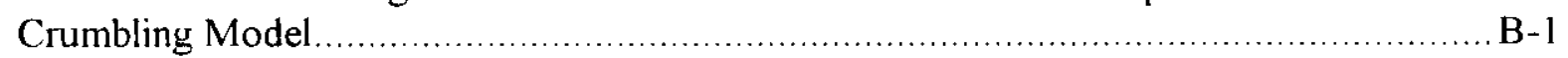

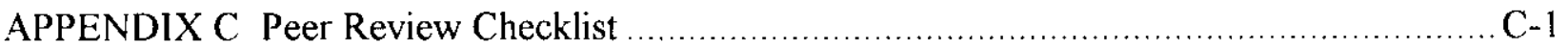




\section{LIST OF FIGURES}

Figure 1. Key Output of Normal Case VPXP7TAG with HANSFy Code ........................... 13

Figure 2. Key Output of Normal Case VPXP7 with HANSF Code, Version 1.3.2.............. 16

Figure 3. Key Output of Normal Case OVLOFTAG with HANSFy Code ............................ 19

Figure 4. Key Output of Normal Case OVLOF with HANSF Code, Version $1.3 .2 \ldots \ldots \ldots \ldots \ldots . . .22$

Figure 5. Key Output of Accident Case VXDGTAG with HANSFy Code ..........................25

Figure 6. Key Output of Accident Case VXDG with HANSF Code, Version 1.3.2 _.............28

Figure 7. Key Output of Accident Case OVLOCTAG with HANSFy Code ........................ 31

Figure 8. Key Output of Accident Case OVLOCXAL with HANSF Code, Version $1.3 .2 \ldots \ldots . .34$

Figure 9. Key Output of Accident Case OVCALTAG with HANSFy Code and Calibrated

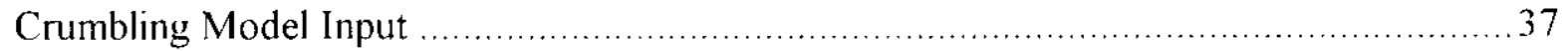

\section{LIST OF TABLES}

1. Results of Cases Using Technical Assistance Group, Calibrated-Technical Assistance Group, and Safety-Basis Fuel Reaction Enhancement Factors Approach. 


\section{LIST OF TERMS}

CVDF

FSAR

MAR

MCO

$\mathrm{SCIC}$

TAG

TGA
Cold Vacuum Drying Facility

final safety analysis report

material at risk

multi-canister overpack

safety-class instrumentation and control

Technical Assistance Group

thermogravimetric analyzer 
SNF-5698 REV 0

This page intentionally left blank. 


\section{COMPARISON OF CALCULATIONAL RESULTS FROM DIFFERENT SPENT NUCLEAR FUEL CRUMBLING APPROACHES}

\subsection{INTRODUCTION}

The purpose of report is to compare results from selected Cold Vacuum Drying Facility (CVDF) cases (both normal and accidental) using three different approaches for incorporating the effects of fuel crumbling in the multi-canister overpack (MCO). Fuel crumbling refers to the breaking up of fuel into smaller pieces and has been observed in some experimental fuel samples with elevated temperatures (PNNL-12167). If fuel crumbles, the total fuel reaction surface area increases. An increase in the reaction surface area causes an increase in the fuel reaction rate which is the product of the reaction surface area and the reaction rate per unit area, which is based on many experiments documented in the literature (HNF-SD-SNF-TI-015). In other words, the fuel-water reaction rate increases when either the reaction surface area increases or the reaction rate per unit area increases. Hence, the surface area increase is often referred to as a reaction rate increase, and the factor of increase over the base values (HNF-SD-SNF-Tl-015) is called a rate multiplier. Safety analyses associated with the CVDF must account for the potential increase in the fuel reaction rate related to fuel crumbling. The three approaches of accounting for fuel crumbling effects that are compared in this document are the following:

1. SNF Project Technical Assistance Group (TAG) Fuel Crumbling Model (Loscoe 1999). The TAG fuel crumbling model explicitly models the growth or increase of fuel reaction surface area due to crumbling as a function of fuel reaction rate which depends on time, fuel temperature, and other parameters (Section 2.1 and Appendix A).

2. Calibrated-TAG Fuel Crumbling Model (Section 2.2 and Appendix A). The calibrated-TAG fuel crumbling model is the same as the TAG model, except that the area growth term is calibrated to the thermogravimetric analyzer (TGA) experimental crumbling data (PNNL-12167).

3. Safety-Basis Fuel Reaction Enhancement Factors (Section 2.3). The safety-basis values of the fuel reaction enhancement factors (HNF-SD-SNF-TI-015) were used in the Spent Nuclear Fuel Project, Cold Vacuum Drying Facility--Amex B. Final Safety Analysis Report (HNF-3553) and other supporting documents (e.g., SNF-5226). The fuel reaction enhancement factors are often referred to more simply as 'rate multipliers.' These enhancement factors implicitly account for fuel crumbling and other physical phenomena or uncertainties that might increase the reaction rates above the reaction rates reported in HNF-SD-SNF-TI-015, Spent Nuclear Finel Project Technical Databook. 
These three fuel crumbling approaches are summarized in Section 2.0, "Fuel Crumbling Approaches," with the TAG and calibrated-TAG fuel crumbling models detailed in Appendix A, "Derivation of Technical Assistance Group Growth Rate of Area Due to Fuel Crumbling."

A fourth fuel crumbling approach, which is based solely on observed data and does not model a specific mechanism, is not included in this document but is described in SNF-5488, Fuel Fracturing (Crumbling) Safety Impact (OCRWM). Since this data-based crumbling approach results in the use of constant rate multipliers, which have smaller values than the safety-basis fuel reaction enhancement factors, this approach was not used explicitly to generate any new results. In other words, the data-based approach for fuel crumbling is bounded by the approach used in the CVDF FSAR (HNF-3553) and other reports (e.g., SNF-2770 and SNF-5226) and is not examined further here.

The safety-basis enhancement factors and the TAG fuel crumbling model are used to simulate normal CVDF operating processes in Section 3.0, "Normal Cases." The calibrated-TAG model is not used for normal cases because the TAG model bounds the calibrated-TAG model and proved to be stable. All three fuel crumbling approaches are used to simulate selected accident cases as described in Section 4.0, "Accident Cases." The summary and conclusion of the comparison are presented in Section 5.0, "Summary and Conclusions." The mathematical derivation of the TAG model is given in Appendix A, along with details of the calibrated-TAG model. Changes to HANSF code (SNF-3650) that were required to implement the TAG and calibrated-TAG models are shown in Appendix B, "Code Changes to HANSF for Technical Assistance Group Fuel Crumbling Model." The revised HANSF Code is denoted as HANSFy. Relocation and other aspects of smaller crumbled pieces of fuel in the $\mathrm{MCO}$ are not included in coding changes.

The results of the comparison indicate that the safety-basis enhancement factors provide bounding (minimal) times for thermal runaway conditions and bounding particulate $\left(\mathrm{UO}_{2}\right)$ generation. The calibrated-TAG model yields bounding temperature extremes (although taking more time to reach those temperatures). However, peak temperatures are a secondary concern because the safety-basis enhancement factors already yield temperatures that must be prevented by CVDF engineered systems. Therefore, the safety-basis enhancement factors provide overall bounding thermal conditions.

\subsection{FUEL CRUMBLING APPROACHES}

Three fuel crumbling approaches were compared: (1) TAG model, (2) calibrated-TAG model, and (3) safety-basis fuel reaction enhancement factors. Each of these approaches is described briefly in this section. 


\subsection{TECHNICAL ASSISTANCE GROUP FUEL CRUMBLING MODEL}

The details of the TAG fuel crumbling model can be found in Technical Assistance Group (TAG) Spent Nuclear Fuel (SNF) Crumbling Model and Recommendations on SNF Crumbling (Loscoe 1999), and a portion of the detailed equations used in the derivation are shown in Appendix A. The model, as used in the HANSF code, is summarized in this section.

The TAG report (Loscoe 1999) does not focus on the initial reaction surface area but on the area growth factor, which is proportional to the fuel reaction rate. In Appendix A, the initial reaction surface area is added to the TAG growth term. In this analysis, three times the initial safety-basis reaction area $\left(3 \times 12 \mathrm{~m}^{2}\right)$ is added to the TAG growth rate of reaction area. The factor of three is a fuel reaction rate enhancement factor used to account for uncertainties in the overall reaction rate from phenomena other than fuel crumbling. The factor of three is implemented in the HANSF code by multiplying it by the fuel reaction surface area, which will increase the reaction rate by a factor of three. This factor of three is large enough to bound all of the fuel-water reaction rate multipliers measured in the TGA experiments (PNNL-12167).

The TAG model's area growth rate per second, $F(T)$, which models the increasing effect of fuel crumbling on reaction area, is multiplied by the geometric reaction area and time (to bound the time integral of $\mathrm{F}(\mathrm{T})$ as shown in Appendix A) and added to three times the initial reaction area to obtain the time-dependent reaction surface area as shown by the following equation:

$$
\begin{aligned}
A(t) & =3 \times A_{g}+t \times F(T) \times A_{g} \\
& =A_{g}(3+t \times F(T))
\end{aligned}
$$

where

$A(t)=$ fuel reaction surface area with TAG fuel crumbling growth term $\left(\mathrm{m}^{2}\right)$

$A_{g}=$ initial safety-basis geometric reaction area $\left(12 \mathrm{~m}^{2}\right.$, HNF-SD-SNF-TI-015)

$\mathrm{t}=$ time that fuel has been crumbling (s)

$F(T)=T A G$ growth factor per second $(1 / \mathrm{s})$, which depends on fuel reaction rate that is a function of fuel temperature and other parameters,

$$
=16.8 \times \operatorname{SQRT}\left(\mathrm{P}_{\mathrm{H} 20}\right) \times \exp (-4937 / \mathrm{T})
$$

$=\mathrm{A}_{\text {rate }} / 3600\left(\mathrm{~A}_{\text {rate }}=\mathrm{TAG}\right.$ growth factor per hour, Equation 6 in Appendix A $)$

$\mathrm{T}=$ fuel temperature $(\mathrm{K})$, which changes over time,

$\mathrm{P}_{\mathrm{H} 2 \mathrm{O}}=$ partial pressure of water vapor in $\mathrm{kPa}$. 
The rate multiplier of the TAG model is simply $A(t) / A_{g}$ which starts at three and increases over time, even with constant fuel temperatures, to some upper bound which is determined below.

\section{Maximum Rate Multiplier}

Since the time-dependent reaction surface area (Equation 1), A(t), can get very large for increasing fuel temperatures and long times, an upper bound had to be determined for the timedependent reaction area, or, equivalently, an upper bound for the reaction rate multiplier had to be determined. If no upper bound is placed on the TAG model's reaction area, then it can exceed $100,000 \mathrm{~m}^{2}$ at very high temperatures $\left(>1000^{\circ} \mathrm{C}\right)$ and long times, which is not physically possible based on the cracked particle size of $0.2 \mathrm{~cm}$ used in the TAG model (Appendix A and Loscoe 1999).

For scrap fuel, the maximum rate multiplier for the TAG model is based on fine scrap fuel. For MCOs with two scrap baskets under accident conditions, thermal runaways have been shown to start in the fine scrap part of the scrap basket (SNF-5226. This is because the fine scrap has a higher surface area to volume ratio than the course scrap fuel pieces or the fuel elements. For simplicity, the initial derivation of maximum rate multiplier for the fine scrap assumes spherically shaped pieces of scrap, and the initially determined rate multiplier is generalized to include other shapes and uncertainties by multiplying by three. This factor of three is analogous to the factor of three applied to the initial reaction surface area described at the beginning of this section.

A piece of fine scrap 1 in. $(2.54 \mathrm{~cm})$ in diameter (the maximum size) can crumble into at most 2,048 smaller $0.2-\mathrm{cm}$ diameter particles (particle size in TAG model) if $100 \%$ of the large piece crumbles. For this complete crumbling, the surface area increases by a factor of 12.7 (surface area of 2,048 small particles divided by surface area of one 2.54-cm-diameter particle). To generalize this factor to include other shapes and uncertainties, the factor is multiplied by three, which gives a final maximum rate multiplier of 38 for the fine scrap fuel.

For the fuel elements in a fuel basket, the maximum rate multiplier is calculated by starting with the area of fuel element for one exposed end of the element (between the cladding). If this initial end area crumbles into smaller $0.2-\mathrm{cm}$ particles (simply assumed to be cubic in shape), the surface will increase by a factor of six (six sides for a cube) for every layer of particles or for every $0.2 \mathrm{~cm}$ of depth or penetration. If the fuel crumbling continues into element for 15 layers of small particles for a total depth of $3 \mathrm{~cm}$, the surface area increases by a factor of $90(15 \times 6)$. The depth of $3 \mathrm{~cm}$ is conservative since it is much larger than the thickness $(<0.9 \mathrm{~cm}$, HNF-SD-SNF-CSER-005) of inner fuel element. Hence, if crumbling occurs on an exposed side of element, the increase of surface area is much smaller ( $<6$ times original) if there is no vertical movement of the crumbling front. By having the fuel crumbling starting on one exposed end of fuel, the surface area increase factor is maximized for all fuel crumbling fronts (both vertical and horizontal). To account for curvature of the element, other shapes of crumbled particles, greater depths, and other uncertainties, the maximum rate multiplier of 90 is multiplied by 3 and results in an overall maximum rate multiplier of 270 for fuel elements. 
In summary, the rate multiplier of 38 for the scrap fuel bounds the maximum surface area increase factor of a crumbled scrap piece. The maximum rate multiplier of 270 for the fuel elements is based on how much crumbling on one end of the fuel can occur (i.e., how deep the element can crumble inside the cladding).

\subsection{CALIBRATED TECHNICAL ASSISTANCE GROUP FUEL CRUMBLING MODEL}

The rate of area growth was recalculated in Appendix A using parameters that were calibrated (Equation 10 in Appendix A) to the crumbling observations in some of the fuel-water reaction TGA experiments (PNNL-12167). The calibrated-TAG model's growth factor (Equation 10 in Appendix A) is $\sim 7.7 \%$ of the uncalibrated-TAG model's growth factor (Equation 6 in Appendix A). In other words, the calibrated growth factor per second $=0.077$ times the TAG growth factor per second shown in Equation 1 (Calibrated-F(t) $=0.077 \times F(t)$ ). The same maximum rate multipliers determined for the TAG model (38 for scrap fuel and 270 for fuel elements) also are applied to the calibrated-TAG model.

\subsection{SAFETY-BASIS FUEL REACTION ENHANCEMENT FACTORS}

The current safety-basis fuel reaction enhancement factors are 10 for the uranium-water reaction and 12 for the uranium hydride-water reaction (HNF-SD-SNF-TI-015). These enhancement factors are intended to bound any uncertainty for all parameters pertaining to reaction rates, including fuel crumbling effects on reaction area and the resulting reaction rates. Therefore, the effects of fuel crumbling are included implicitly in the safety-basis fuel reaction enhancement factors.

\subsection{NORMAL CASES}

The TAG fuel crumbling model (Loscoe 1999) was implemented in a derivative of the HANSF code, version 1.3.2 (Appendix B). The normal cases were simulated to show that the TAG fuel crumbling model would not change normal conditions.

The two normal cases are the following:

1. Case VPXP7TAG includes normal vacuum pumping $\left(30 \mathrm{ft}^{3} / \mathrm{min}\right)$ with helium purge rate of 0.7 standard $\mathrm{ft}^{3} / \mathrm{min}$.

2. Case OVLOFTAG has stationary annulus water (i.e., loss of annulus water flow). 


\subsection{CASE VPXP7TAG}

Case VPXP7TAG has continuous vacuum pumping and helium purge, which differs from the normal 8-4-4 cycle in the sense that the $4 \mathrm{~h}$ of helium purge only is not included. The 8-4-4 vacuum-purge cycle is more thermally stable than just the continuous vacuum with helium purge operation by itself (SNF-5226, Appendix B). Hence, if case VPXP7TAG fuel temperatures remain thermally stable, then the fuel temperatures from the 8-4-4 cycle will also be stable.

As shown in Figure 1, the fuel temperatures for case VPXP7TAG are very stable with a peak fuel temperature of only $64{ }^{\circ} \mathrm{C}$. This peak fuel temperature is lower than the previously documented case VPXP7 (SNF-5226) with the safety-basis fuel reaction enhancement factors, which had a peak fuel temperature of $71{ }^{\circ} \mathrm{C}$ (see Figure 2). This is expected since the safety-basis enhancement factors are higher than the rate multipliers from the TAG model for early times. For later times (i.e., larger $t$ in Equation 1), the TAG fuel crumbling model has higher rate multipliers (see Equation 1), but the MCO is dry at later times due to vacuum pumping removing the water in $\sim 14 \mathrm{~h}$. The key result is that the TAG crumbling model does not cause any thermal off-normal behavior to occur in the normal vacuum drying case (case VPXP7 in SNF-5226).

\subsection{CASE OVLOFTAG}

Case OVLOFTAG is a conservative MCO isolation and purge, which is activated by the Safety Class Instrumentation and Control (SCIC) System upon detection of off-normal conditions. Under certain off-normal conditions, the SCIC System isolates (in regards to vacuum pumping, draining, etc.) the $\mathrm{MCO}$ and activates a $\mathrm{SCHe}$ purge that puts the $\mathrm{MCO}$ under a helium pressure (HNF-3553, Chapter B2.0). Case OVLOFTAG is conservative in the sense that the helium purge is not included and the annulus water is not flowing; both of these processes would result in cooler fuel temperatures. Case OVLOF is the same as case OVLOFTAG except that the safety-basis fuel reaction enhancement factors are employed instead of the TAG fuel crumbling model (Equation 1). The process bay, which is the heat sink when annulus water is stationary, is at a temperature of $26.7^{\circ} \mathrm{C}\left(80^{\circ} \mathrm{F}\right)$ for both of these cases.

As shown in Figure 3, the fuel temperatures for case OVLOFTAG are stable for at least 4 days $(96 \mathrm{~h})$ with a maximum fuel temperature of $72.5^{\circ} \mathrm{C}$. For case OVLOF, the maximum fuel temperature is $75^{\circ} \mathrm{C}$ (see Figure 4), which is slightly higher than the $72.5^{\circ} \mathrm{C}$ from case OVLOFTAG. The key result is that the TAG fuel crumbling model will not cause any thermal off-normal behavior to occur in the MCO isolation and purge case (OVLOF).

\subsection{ACCIDENT CASES}

For the accident cases, several outputs of interest were chosen for comparisons. These outputs were the peak temperatures for fuel, MCO center post and wall, the time to recover from 
the accident and prevent its progression, and the material at risk (MAR) generated that is used in the radiological consequence analysis.

Three accident cases were simulated and compared to previously documented accident cases or with each other:

1. VXDGTAG - Degraded vacuum $\left(13 \mathrm{ft}^{3} / \mathrm{min}\right)$ and no helium purge; compares to previously documented case VXDG (SNF-5226)

2. OVLOCTAG - Loss of annulus water, MCO has open vent; compares to previously documented case OVLOCXAL (SNF-5526; HNF-3553, Chapter B3.0)

3. OVCALTAG - Loss of annulus water, open vent on MCO, and calibrated-TAG fuel crumbling model is employed; compares to case OVLOCTAG above and previous case OVLOCXAL (SNF-5226; HNF-3553, Chapter B3.0).

\subsection{CASE VXDGTAG}

The degraded vacuum case has a degraded vacuum pumping rate of only $13 \mathrm{ft}^{3} / \mathrm{min}$ instead of normal rate, which is at least $30 \mathrm{ft}^{3} / \mathrm{min}$. Also, the suction effects of the vapor condenser and the stabilization effects of the helium purge are conservatively excluded from this case. The degraded vacuum case with the TAG fuel crumbling model (VXDGTAG) has stable temperatures with a peak fuel temperature of $75^{\circ} \mathrm{C}$ as shown in Figure 5. This stable fuel temperature is much different and more benign than the fuel temperatures from the previously documented degraded vacuum case (VXDG, SNF-5226), which shows a thermal excursion starting at $15.5 \mathrm{~h}$ and peaking around $17.5 \mathrm{~h}$ with a peak fuel temperature of $740{ }^{\circ} \mathrm{C}$ (see Figure 6). Also, the particulate or MAR generated by the TAG model case is smaller $(\sim 1.2 \mathrm{~kg}$ $\left.\mathrm{UO}_{2}\right)$ than the MAR generated by the safety-basis fuel reaction enhancement factors $(\sim 40 \mathrm{~kg}$ $\mathrm{UO}_{2}$ ). In other words, the safety-basis fuel reaction enhancement factors approach is more conservative than the TAG fuel crumbling model for the degraded vacuum scenario in regards to both fuel temperatures and MAR generation. The safety-basis fuel reaction enhancement factors are higher than the TAG model's rate multipliers for early times when water is present and reacting. The TAG model's rate multipliers are higher at a much later time, but at later times the water is no longer present $(\sim 22 \mathrm{~h})$ due to degraded vacuum pumping. In summary, the TAG fuel crumbling model is more benign than the safety-basis fuel reaction enhancement factor approach for the degraded vacuum scenario.

\subsection{CASE OVLOCTAG}

The high temperature case consists of an open vented $\mathrm{MCO}$ with no annulus water present between the MCO and cask. Air has filled the annulus and has taken the place of water. Since the thermal conductivity of air is much smaller than the conductivity of water, heat builds up in the $\mathrm{MCO}$, causing higher temperatures that increase the reaction rates. The TAG fuel crumbling 
model is used in case OVLOCTAG, and the results are compared to the previously documented case OVLOCXAL (SNF-5226), which is the high temperature design basis accident in the CVDF FSAR (HNF-3553, Chapter B3.0). Both of these cases include the effects of the thermal decomposition of bounding aluminum hydroxide, which releases more water for oxidation of the fuel. The effect of decomposing aluminum hydroxide has been shown to be small (SNF-5226).

The peak fuel temperatures of the TAG model case (OVLOCTAG) are higher (see Figure 7) than the peak fuel temperatures of the safety-basis fuel reaction enhancement factors case (OVLOCXAL, Figure 8). However, both cases produce very high fuel temperatures $\left(>1000^{\circ} \mathrm{C}\right)$, and the HANSF code has been shown to be conservative in regard to calculating high temperatures (SNF-5226). For other outputs of interest, the time to reach $700{ }^{\circ} \mathrm{C}$ is considered to be the most time allowed to recover from the loss of annulus water event by adding water, which has been shown to be a very effective recovery (HNF-SD-SNF-CN-023). The time to reach a $700^{\circ} \mathrm{C}$ fuel temperature is much longer $(\sim 22 \mathrm{~h})$ for the TAG model than for the safetybasis fuel reaction enhancement factors approach $(\sim 11 \mathrm{~h})$, which makes the safety-basis enhancement factors more conservative than the TAG model. Also the MAR, which is the particulate generated during oxidation, is smaller $(155 \mathrm{~kg} \mathrm{UO} 2)$ with the use of TAG model than with the safety-basis fuel reaction enhancement factors $\left(163 \mathrm{~kg} \mathrm{UO}_{2}\right)$. This means that the TAG model case will cause slightly lower dose consequences than the safety-basis fuel reaction enhancement factors approach, which was used in the CVDF FSAR (HNF-3553, Chapter B3.0). In summary, the TAG model is more conservative than the safety-basis fuel reaction enhancement factors approach in regard to high fuel temperatures, but is more benign than the safety-basis enhancement factors in regard to recovery time of lost annulus water and the amount of the MAR used for dose consequences. The recovery time and MAR are considered more important to safety than high fuel temperatures, especially since the peak fuel temperatures are high using either fuel crumbling approach.

\subsection{CASE OVCALTAG}

The high temperature case with the calibrated-TAG fuel crumbling model (OVCALTAG) is the same as the previous case (OVLOCTAG) with loss of annulus water, except that the calibrated-TAG model (Section 2.3) is used instead of the original TAG model (Section 2.2). In review, the calibrated-TAG model has a growth factor for reaction area, due to crumbling, that is about $7.7 \%$ of the original TAG model growth factor. Since the fuel temperatures were stable for all the normal cases and the degraded vacuum with no helium accident case using the more conservative TAG model, the less conservative calibrated-TAG model was not used for those cases.

The high temperature case with the calibrated-TAG model (case OVCALTAG) produces high temperatures (see Figure 9) like the original TAG model case (OVLOCTAG) described previously. However, the recovery time (time for peak fuel temperature to reach $700^{\circ} \mathrm{C}$ ) for the calibrated-TAG model is much longer $(\sim 54 \mathrm{~h})$ than the TAG model recovery time $(\sim 22 \mathrm{~h})$ and the safety-basis fuel reaction enhancement factors recovery time $(\sim 11 \mathrm{~h}$, case OVLOCXAL). The 
MAR from the calibrated-TAG model case (OVCALTAG) is larger than the MAR from the other cases, but it is over a much longer time period of $60 \mathrm{~h}$ instead of only $24 \mathrm{~h}$. This is because the water for reaction with fuel collects at the bottom of the MCO and does not flow out of the open vent on top of the MCO until high temperatures result and water is vaporized, which is much later for the calibrated-TAG model case. As a result, the water reacts for a longer time period at cooler temperatures with the calibrated-TAG model. In summary, the calibrated-TAG fuel crumbling model results in similar high temperatures as the TAG model and in a higher MAR over a longer time period, but results in a much longer recovery time than the other high temperature cases (OVLOCTAG and OVLOCXAL).

\subsection{SUMMARY AND CONCLUSIONS}

The results for the chosen results of interest for all three fuel crumbling approaches are summarized in Table 1 for all normal and accident cases analyzed. For normal CVDF operations, the TAG and calibrated-TAG models did not result in any upset or off-normal conditions. Hence, the TAG and calibrated-TAG models have no effect on simulations of normal operations. For accident conditions, the TAG fuel crumbling model is not as conservative as the safety-basis fuel reaction enhancement factors used in previous reports (SNF-5226) including the CVDF FSAR (HNF-3553, Annex B) in regards to the most important outputs of interest (recovery time and MAR generation). While the calculated peak temperatures are higher using the TAG and calibrated-TAG models, the temperatures predicted by the safety-basis enhancement factors are already higher than temperatures that are acceptable and are prevented by the CVDF Safety Systems. In conclusion, the safety-basis fuel enhancement factors approach to account for fuel crumbling effects clearly bounds the results of interest from TAG fuel crumbling model for both normal and accident cases. 
Table 1. Results of Cases Using Technical Assistance Group, Calibrated-Technical Assistance Group, and Safety-Basis Fuel Reaction Enhancement Factors Approaches. ${ }^{a}$

\begin{tabular}{|c|c|c|c|c|c|c|}
\hline $\begin{array}{l}\text { Case } \\
\text { Name }\end{array}$ & $\begin{array}{l}\text { Crumbling } \\
\text { Approach }\end{array}$ & $\begin{array}{c}\text { Peak Fuel } \\
\text { Tempcrature } \\
\left({ }^{\circ} \mathrm{C}\right)\end{array}$ & $\begin{array}{l}\text { Peak Center } \\
\text { Post } \\
\text { Temperature } \\
\left({ }^{\circ} \mathrm{C}\right)\end{array}$ & $\begin{array}{l}\text { Peak Wall } \\
\text { Temperature } \\
\left({ }^{\circ} \mathrm{C}\right)\end{array}$ & $\begin{array}{l}\text { Recovery } \\
\text { Time (h) }\end{array}$ & $\begin{array}{c}\mathrm{MAR}- \\
\mathrm{UO}_{2}(\mathrm{~kg})\end{array}$ \\
\hline \multicolumn{7}{|c|}{ NORMAL CASES } \\
\hline $\begin{array}{l}\text { VPXP7TAG } \\
\text { Vacuum and } \\
\text { helium }\end{array}$ & TAG & 64 & 60 & 50 & $\begin{array}{l}\text { NA, } \\
\text { Stable }\end{array}$ & $\begin{array}{c}0.35 \text { for } \\
24 \mathrm{~h}\end{array}$ \\
\hline $\begin{array}{l}\text { VPXP7 Vacuum } \\
\text { only }\end{array}$ & $\begin{array}{l}\text { Safety } \\
\text { basis }\end{array}$ & 71 & 70 & 50 & $\begin{array}{l}\text { NA, } \\
\text { Stable }\end{array}$ & $\begin{array}{l}2.8 \text { for } \\
24 \mathrm{~h}\end{array}$ \\
\hline $\begin{array}{l}\text { OVLOFTAG } \\
\text { Shut down }\end{array}$ & TAG & 72.5 & 71.5 & 50.5 & $\begin{array}{l}\text { NA, } \\
\text { Stable }\end{array}$ & $\begin{array}{l}7.1 \text { for } \\
96 \mathrm{~h}\end{array}$ \\
\hline $\begin{array}{l}\text { OVLOF } \\
\text { Shut down }\end{array}$ & $\begin{array}{l}\text { Safety } \\
\text { basis }\end{array}$ & 75 & 74 & $5 \mathrm{l}$ & $\begin{array}{l}\text { NA, } \\
\text { Stable }\end{array}$ & $\begin{array}{l}30.5 \text { for } \\
24 \mathrm{~h}\end{array}$ \\
\hline \multicolumn{7}{|c|}{ ACCIDENT CASES } \\
\hline $\begin{array}{l}\text { VXDGTAG } \\
\text { Degraded } \\
\text { vacuum only }\end{array}$ & $\mathrm{TAG}$ & 75 & 69 & 50 & $\begin{array}{l}\text { NA, } \\
\text { Stable }\end{array}$ & $\begin{array}{l}1.2 \text { for } \\
24 \mathrm{~h}\end{array}$ \\
\hline $\begin{array}{l}\text { VXDG } \\
\text { Degraded } \\
\text { vacuum only }\end{array}$ & $\begin{array}{l}\text { Safety } \\
\text { basis }\end{array}$ & 740 & 725 & 50 & NA & $\begin{array}{l}40 \text { for } \\
24 \mathrm{~h}\end{array}$ \\
\hline $\begin{array}{l}\text { OVLOCTAG } \\
\text { Loss of annulus }\end{array}$ & TAG & $>1100^{\mathrm{b}}$ & $>1100$ & 750 & 22 & $\begin{array}{l}155 \text { for } \\
24 \mathrm{~h}\end{array}$ \\
\hline $\begin{array}{l}\text { OVLOCXAL } \\
\text { Loss of annulus }\end{array}$ & $\begin{array}{l}\text { Safety } \\
\text { basis }\end{array}$ & 1010 & 995 & 520 & 11 & $\begin{array}{l}163 \text { for } \\
24 \mathrm{~h}\end{array}$ \\
\hline $\begin{array}{l}\text { OVCALTAG } \\
\text { Loss of annulus }\end{array}$ & $\begin{array}{l}\text { Calibrated- } \\
\text { TAG }\end{array}$ & $>1100^{\mathrm{b}}$ & $>1100$ & 850 & 54 & $\begin{array}{l}196 \text { for } \\
60 \mathrm{~h}\end{array}$ \\
\hline
\end{tabular}

${ }^{a}$ Calibrated-TAG model for the degraded vacuum case was not run since it is bounded by TAG model case VXDGTAG.

${ }^{b} 1100^{\circ} \mathrm{C}$ is the approximate melting temperature of uranium, and melting phenomena is not included in HANSF code (SNF-3650), so exact temperatures above $1100^{\circ} \mathrm{C}$ are not reported.

$\mathrm{MAR}=$ material at risk.

NA $=$ not applicable

$\mathrm{TAG}=$ Technical Assistance Group. 


\subsection{REFERENCES}

HNF-3553, Annex B, 2000, Spent Nuclear Fuel Project, Cold Vacuum Drying Facility Annex B, Final Safety Analysis Report, Rev. 0, Fluor Daniel Hanford, Incorporated, Richland, Washington.

HNF-SD-SNF-CN-023, 1998, Thermal Analysis of Cold Vacum Drying of Spent Nuclear Fuel, Rev. 1, Fluor Daniel Hanford, Incorporated, Richland, Washington.

HNF-SD-SNF-CSER-005, 1999, Criticality Safety Evaluation Report for the Multi-Canister Overpack, Rev. 5, Fluor Daniel Hanford, Incorporated, Richland, Washington.

HNF-SD-SNF-TI-015, 1998, Spent Nuclear Finel Project Technical Databook, Rev. 6, Fluor Daniel Hanford, Incorporated, Richland, Washington.

Loscoe, P. G., 1999, ('ontract No. DE-A(06-96RL13200) Technical Assistance (iroup (TAG) Spent Nuclear Fuel (SNF) Crumbling Model and Recommendations on SNF (rumbling (Letter 00-SFO-034 to R. D. Hanson, Fluor Daniel Hanford, Incorporated, November 19), U.S. Department of Energy, Richland Operations Office, Richland, Washington.

PNNL-12167, 1999, Oxidation of K-West Basin Spent Nuclear Fuel in Moist Helium Atmosphere, Pacific Northwest National Laboratory, Richland, Washington.

SNF-3650, 1999, HANSF 1.3.2 User's Mamal, Rev. 2, Fluor Daniel Hanford, Incorporated, Richland, Washington.

SNF-5226, 1999, Comparison Cases Simulated with HANSF 1.3.2 to Supplemen Thermal Analyses Documented in HNF-SD-SNF-(N-023, Rev. 0, Fluor Daniel Hanford, Incorporated, Richland, Washington.

SNF-5488, 2000, Fuel Fracturing ((rumbling) Safety Impact (()(RWM), Rev. I, Fluor Daniel Hanford, Incorporated, Richland, Washington. 
SNF-5698 REV 0

This page intentionally left blank. 
Figure 1. Key Output of Normal Case VPXP7TAG with HANSFy Code. ( 1 of 3 sheets)
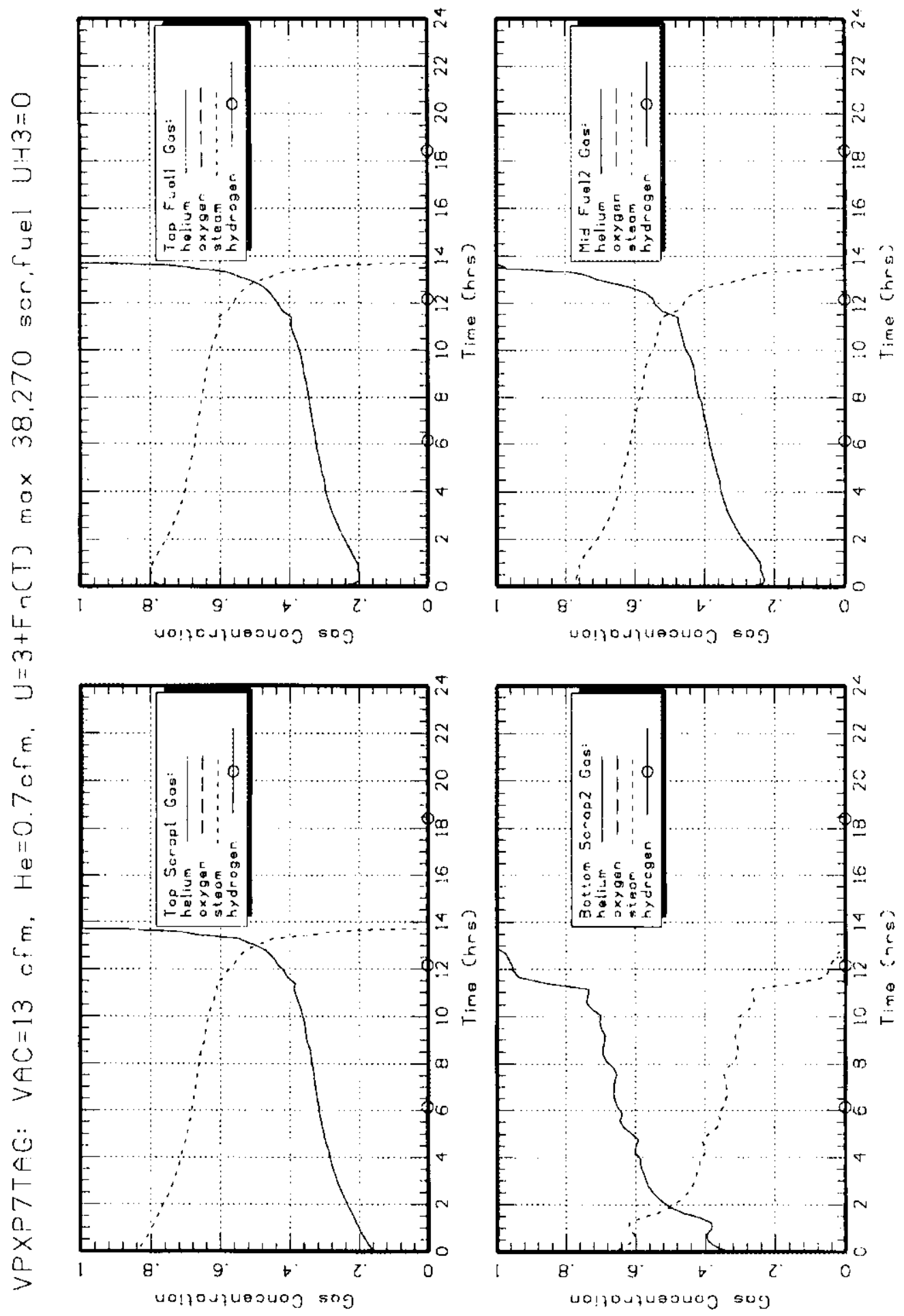
Figure 1. Key Output of Normal Case VPXP7TAG with HANSFy Code. (2 of 3 sheets)

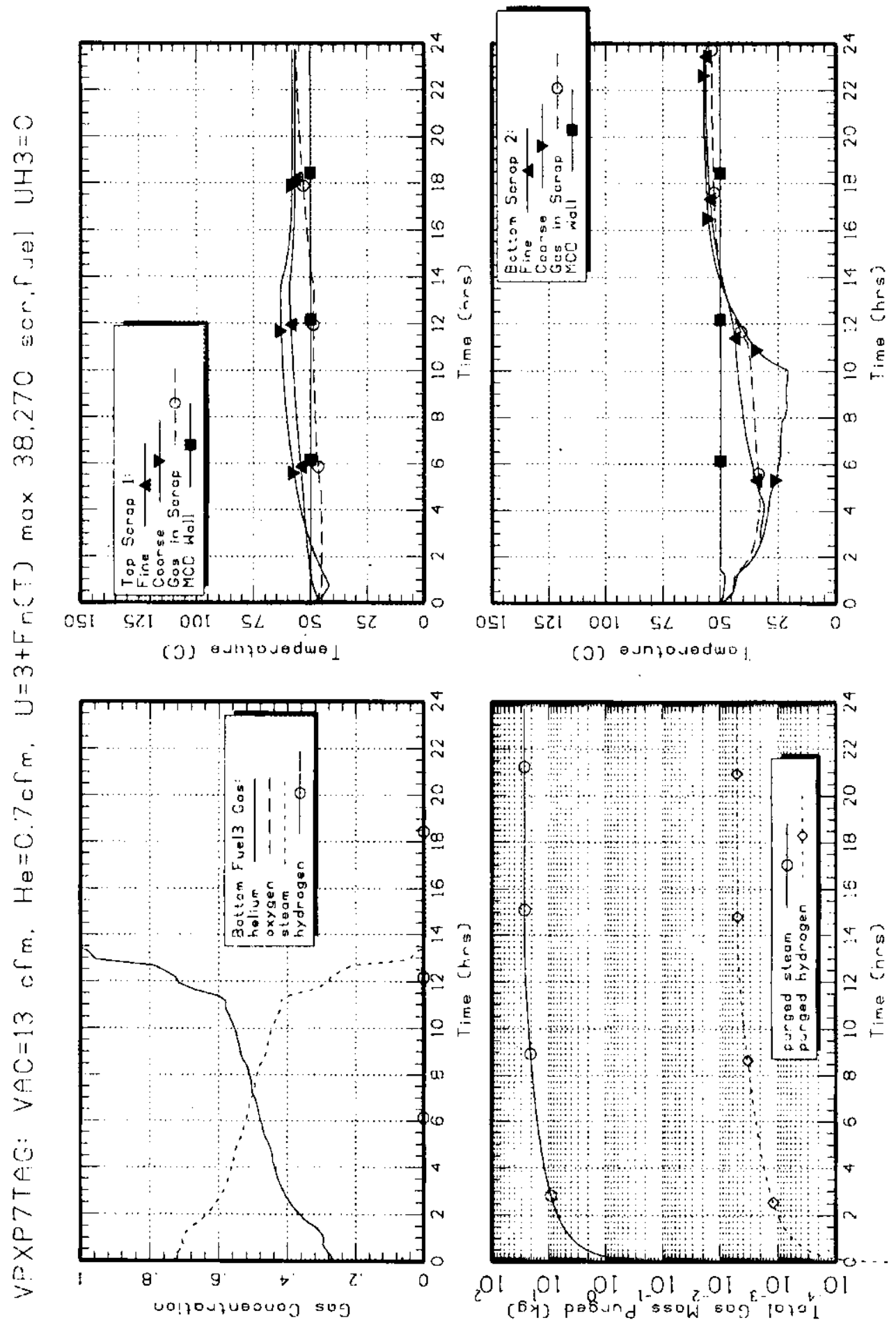


Figure 1. Key Output of Normal Case VPXP7TAG with HANSFy Code. (3 of 3 sheets)
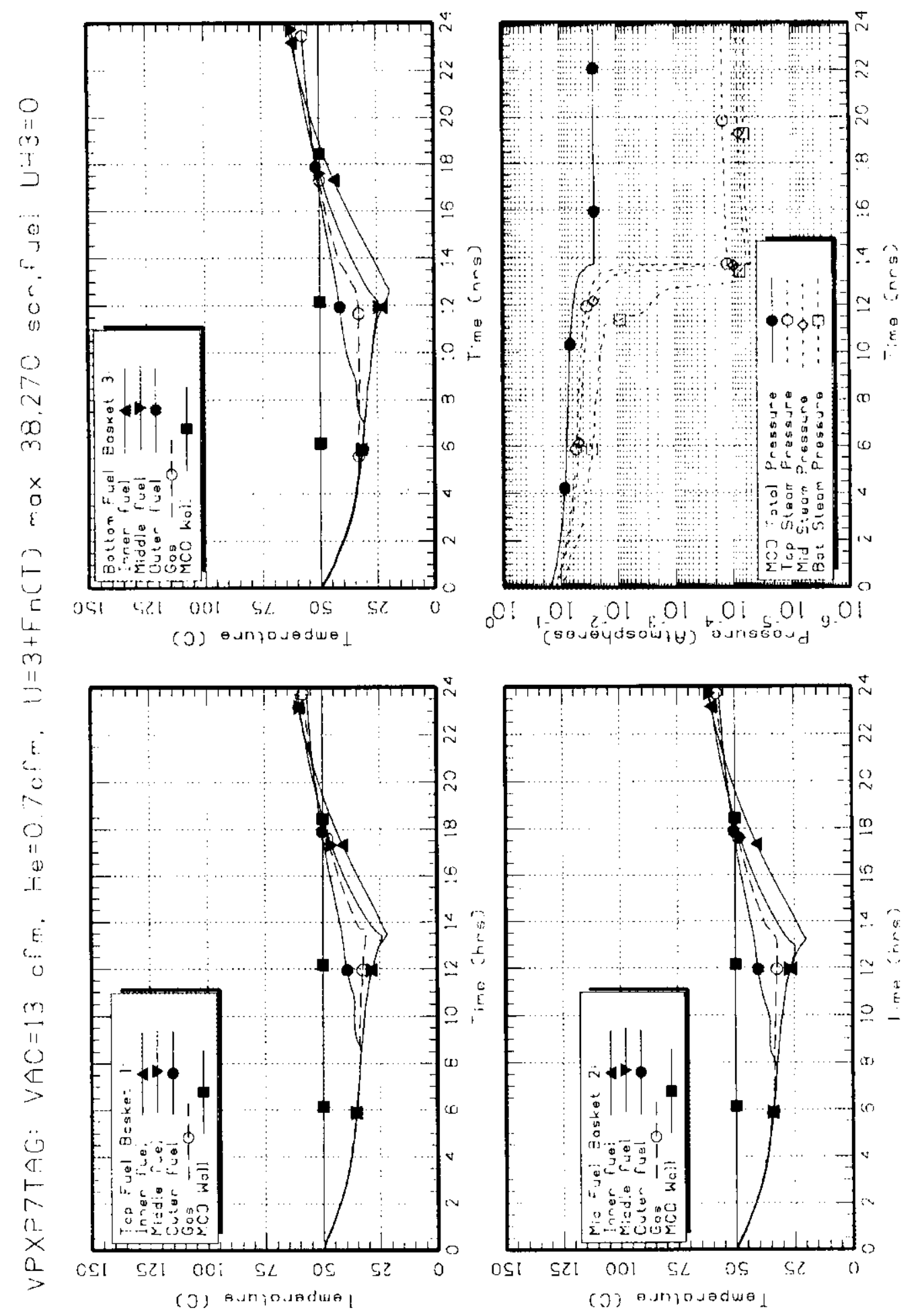
Figure 2. Key Output of Normal Case VPXP7 with HANSF Code, Version 1.3.2. (1 of 3 sheets)
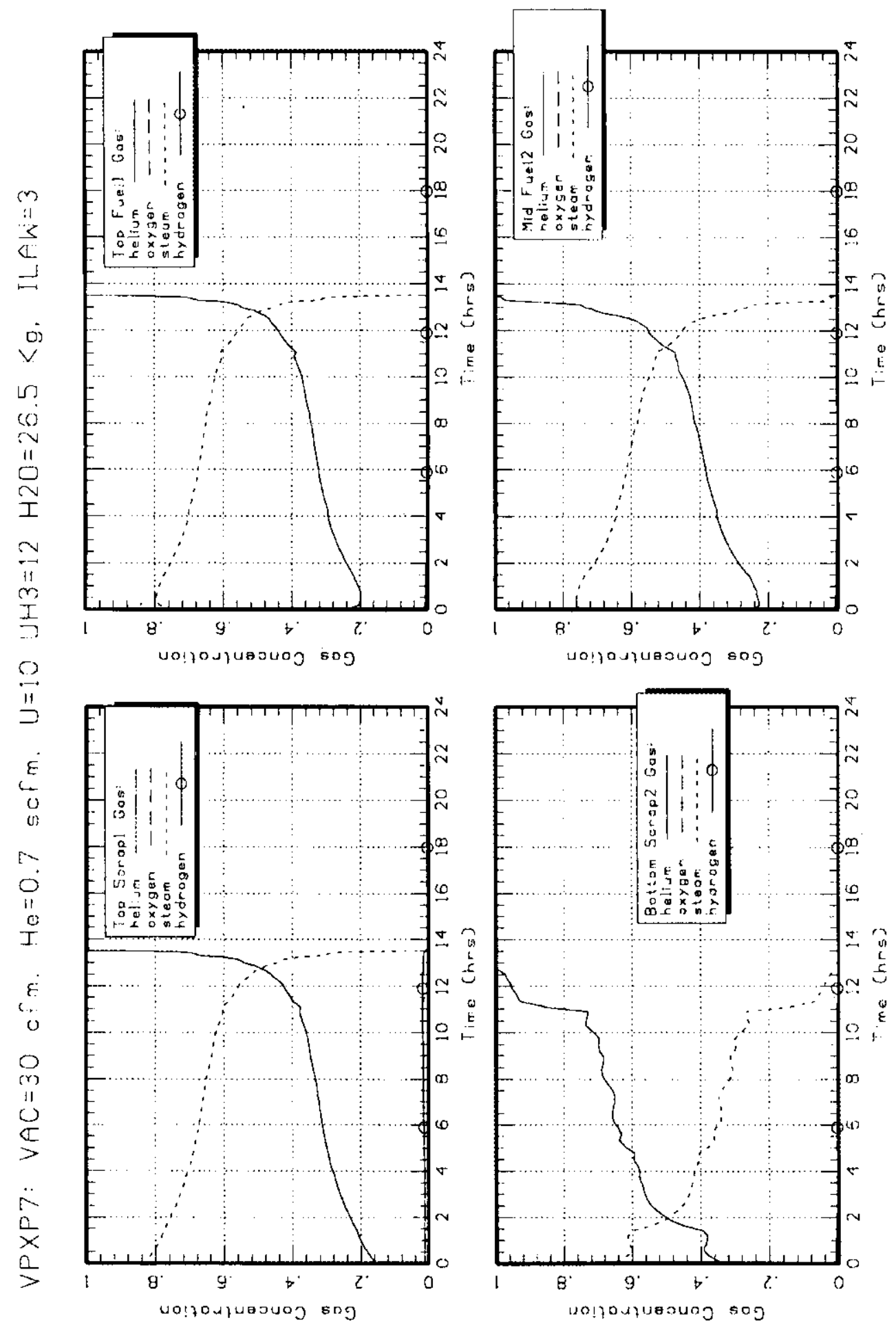

snf-5698.doc 
Figure 2. Key Output of Normal Case VPXP7 with HANSF Code, Version 1.3.2. (2 of 3 sheets)
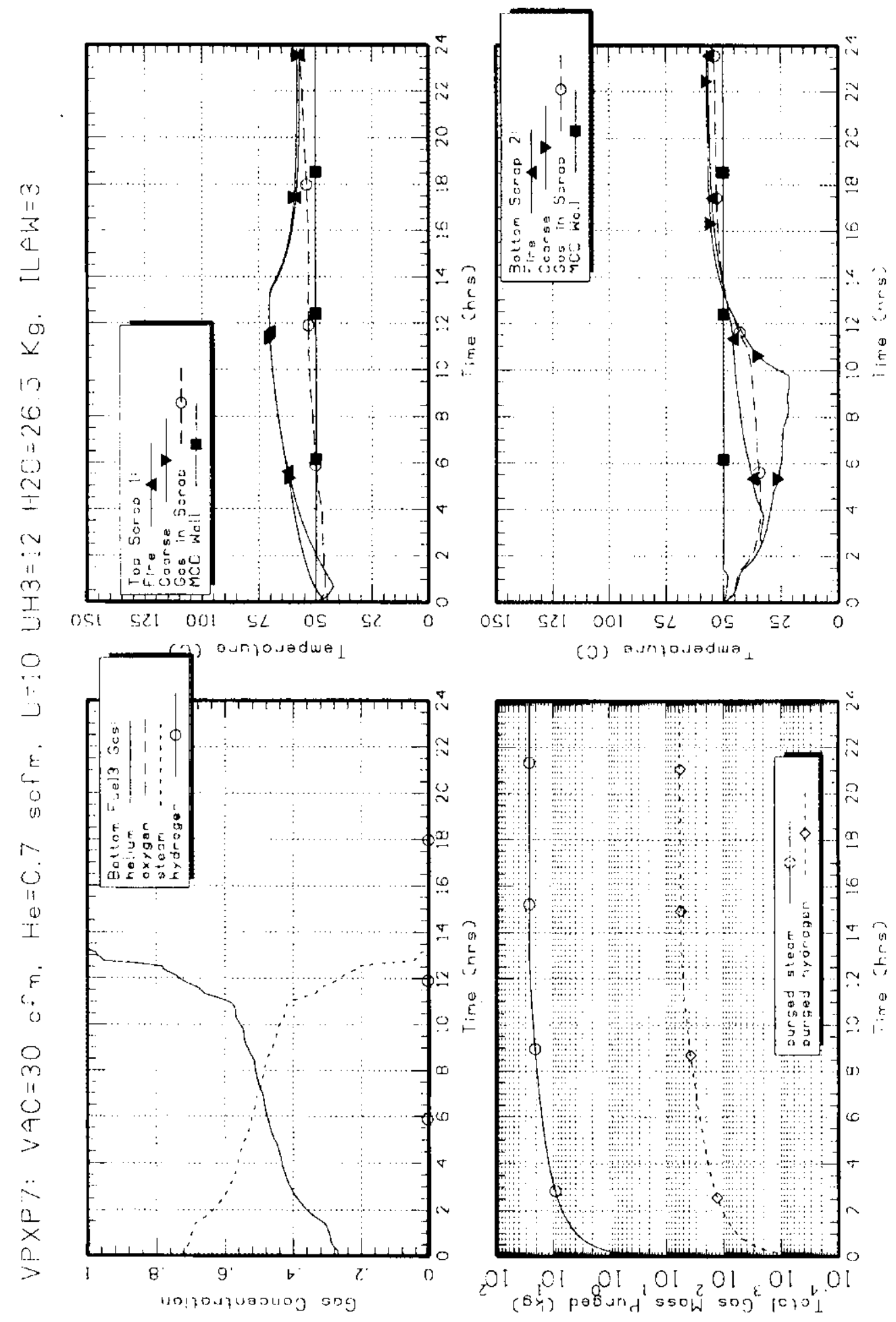
Figure 2. Key Output of Normal Case VPXP7 with HANSF Code, Version 1.3.2. (3 of 3 sheets)
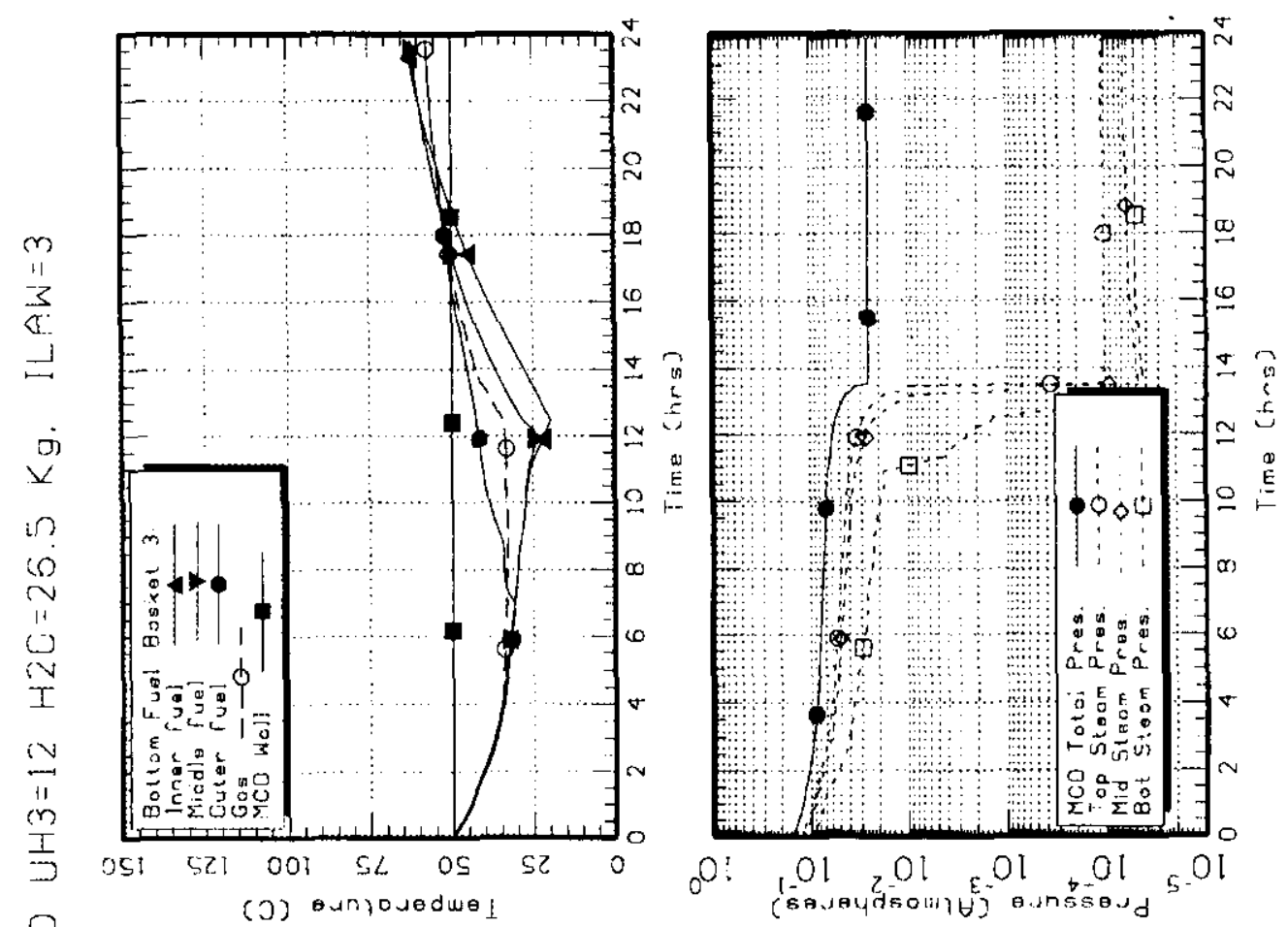

?
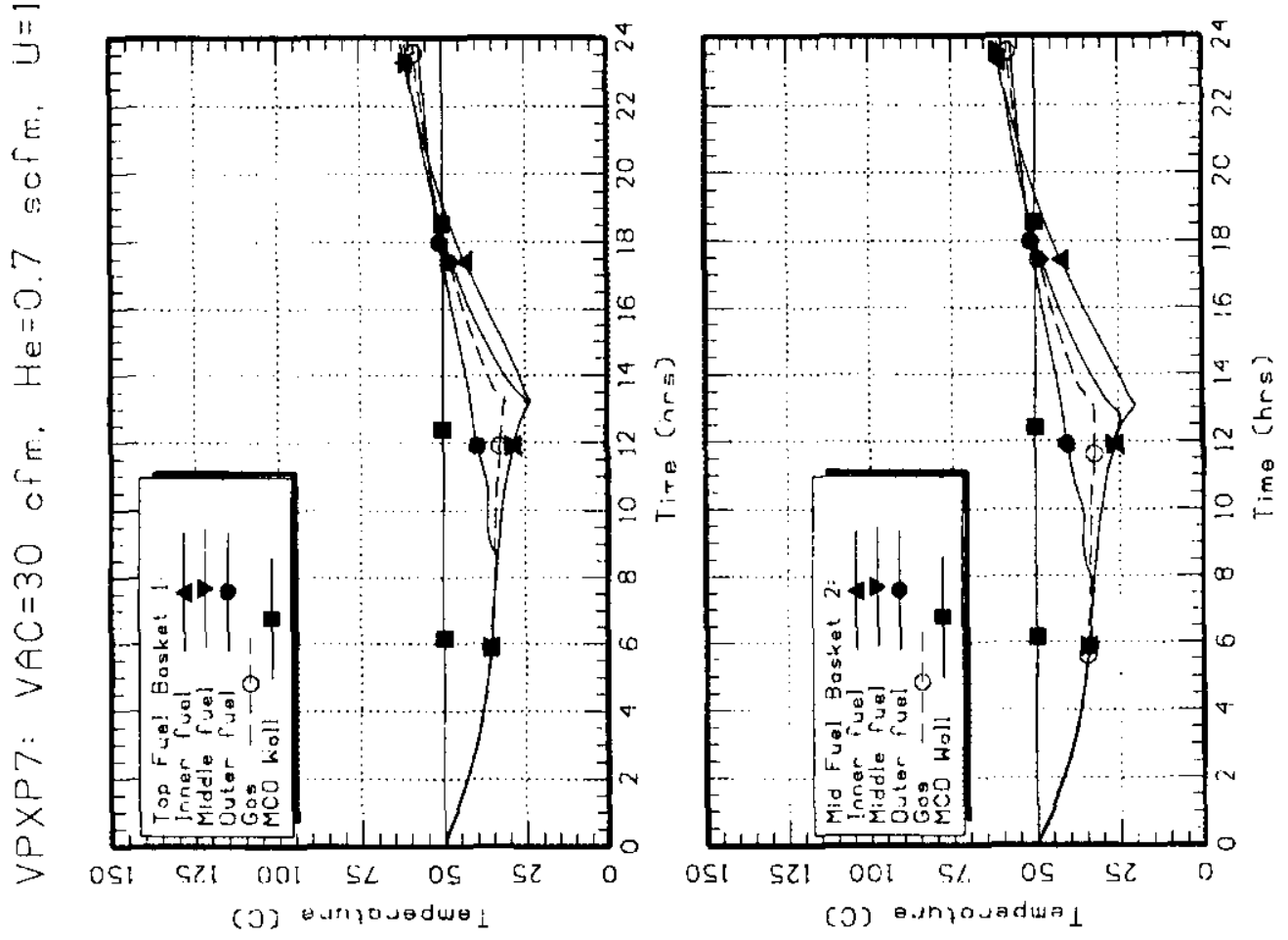
Figure 3. Key Output of Normal Case OVLOFTAG with HANSFy Code. ( 1 of 3 sheets)

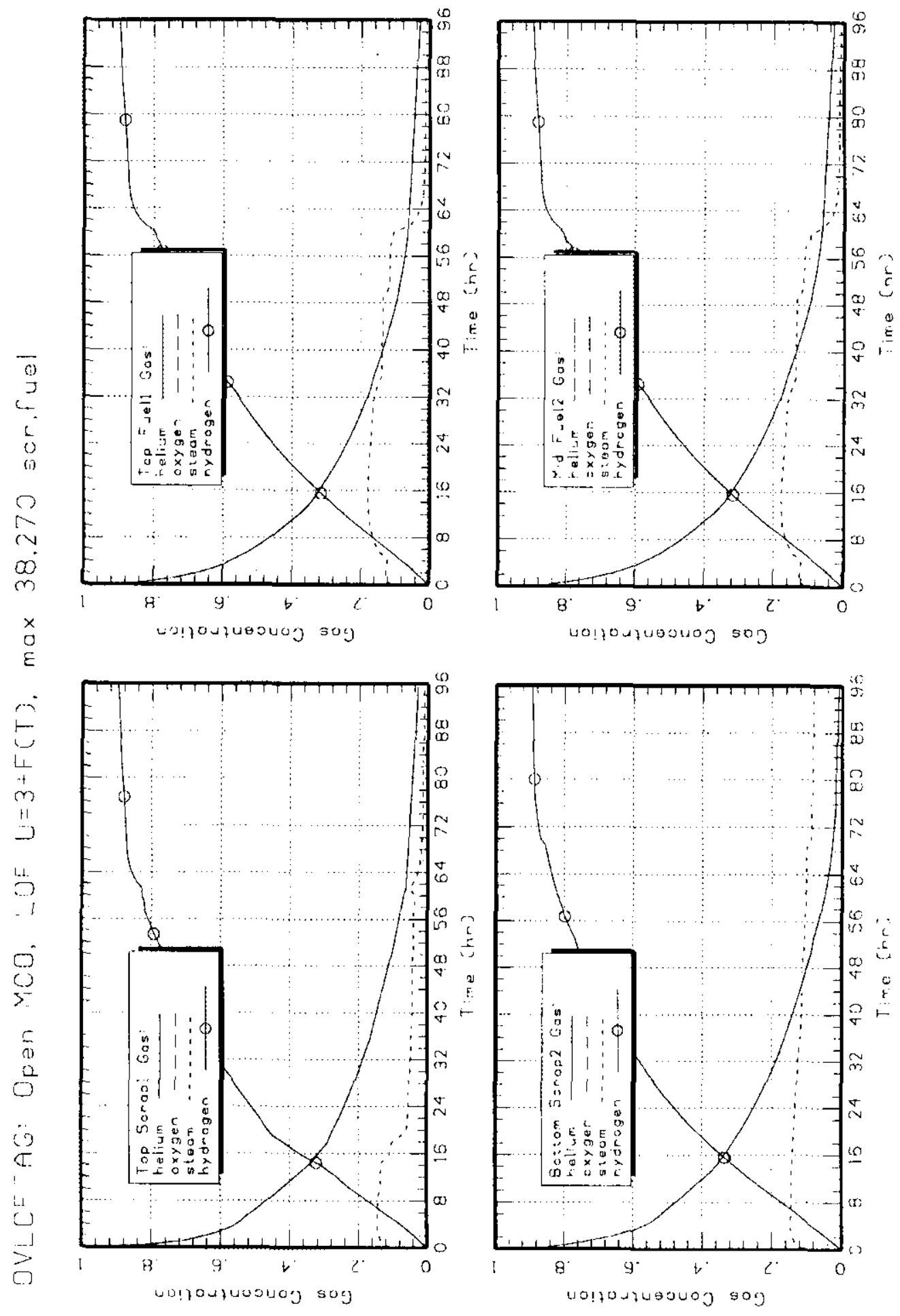


Figure 3. Key Output of Normal Case OVLOFTAG with HANSFy Code. (2 of 3 sheets)

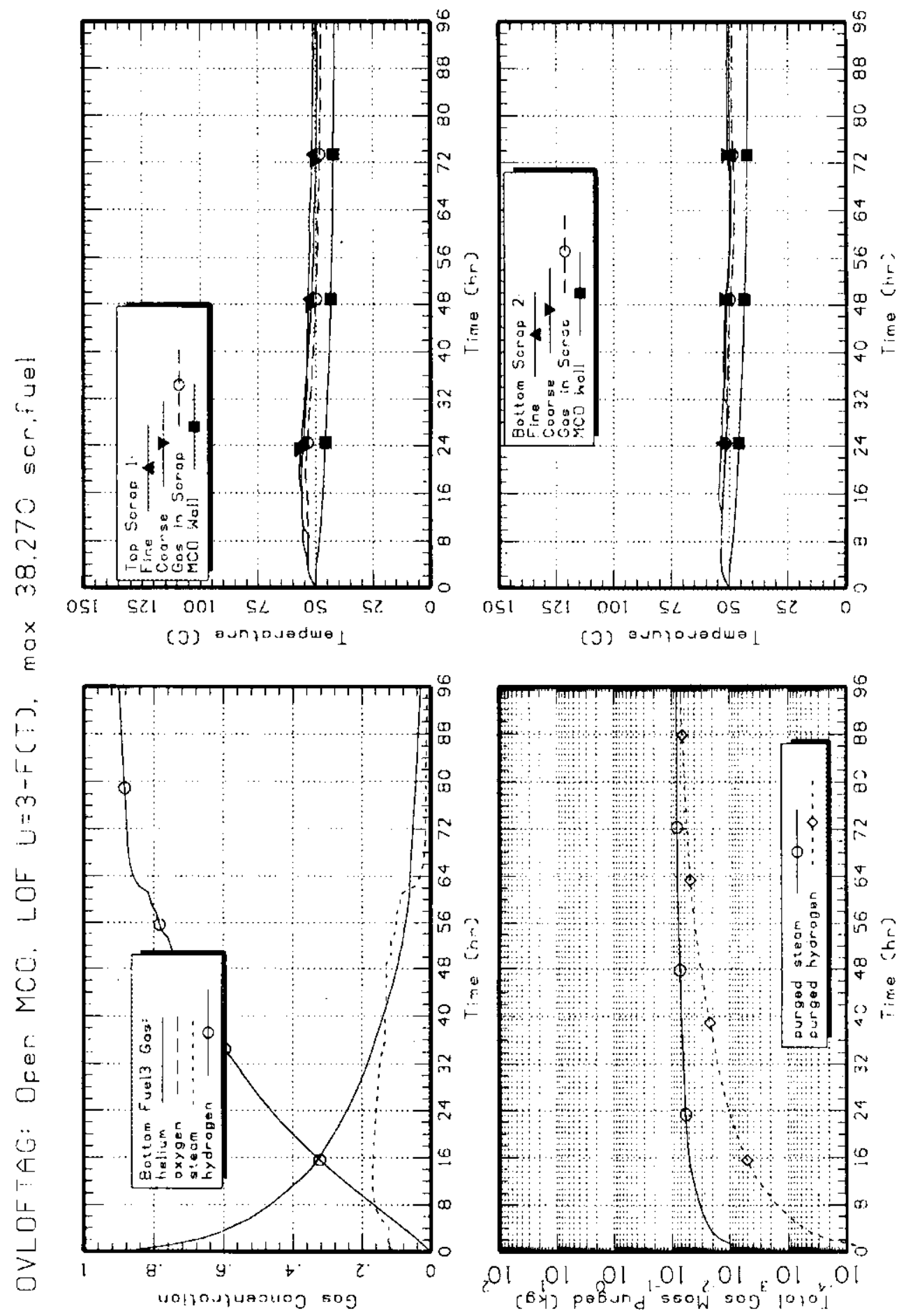


Figure 3. Key Output of Normal Case OVLOFTAG with HANSFy Code. (3 of 3 sheets)

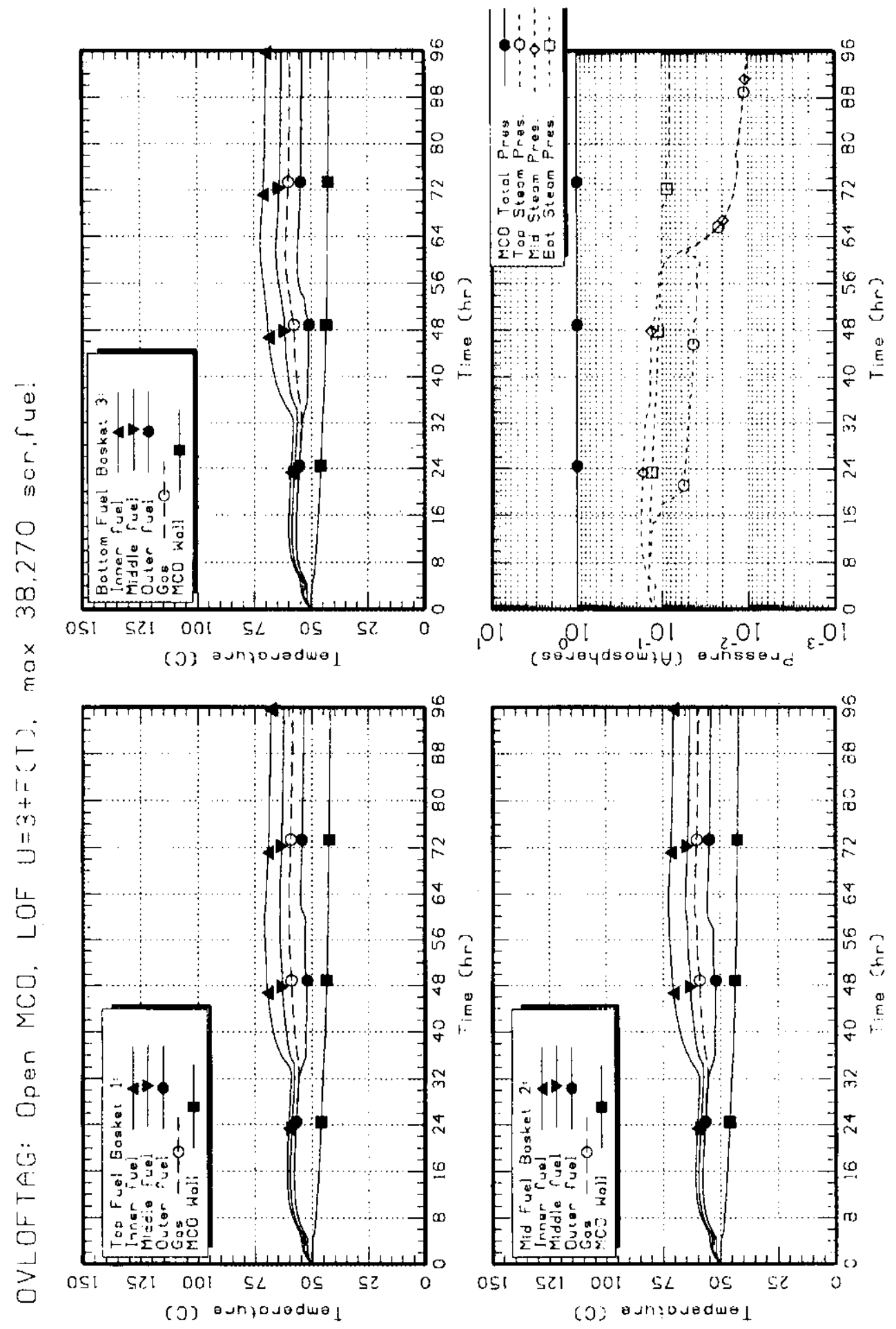


Figure 4. Key Output of Normal Case OVLOF with HANSF Code, Version 1.3.2. ( 1 of 3 sheets)

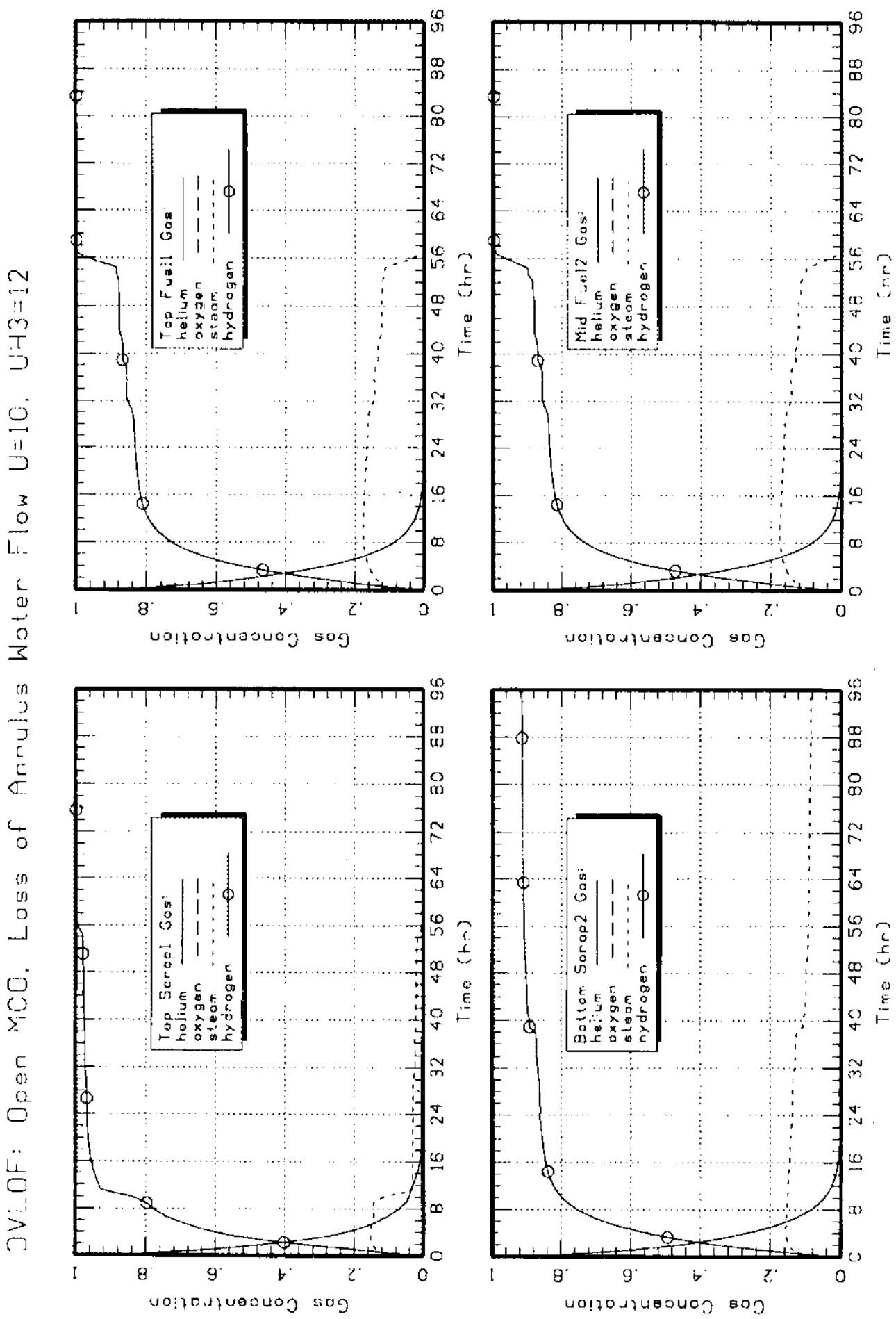


Figure 4. Key Output of Normal Case OVLOF with HANSF Code, Version 1.3.2. ( 2 of 3 sheets)
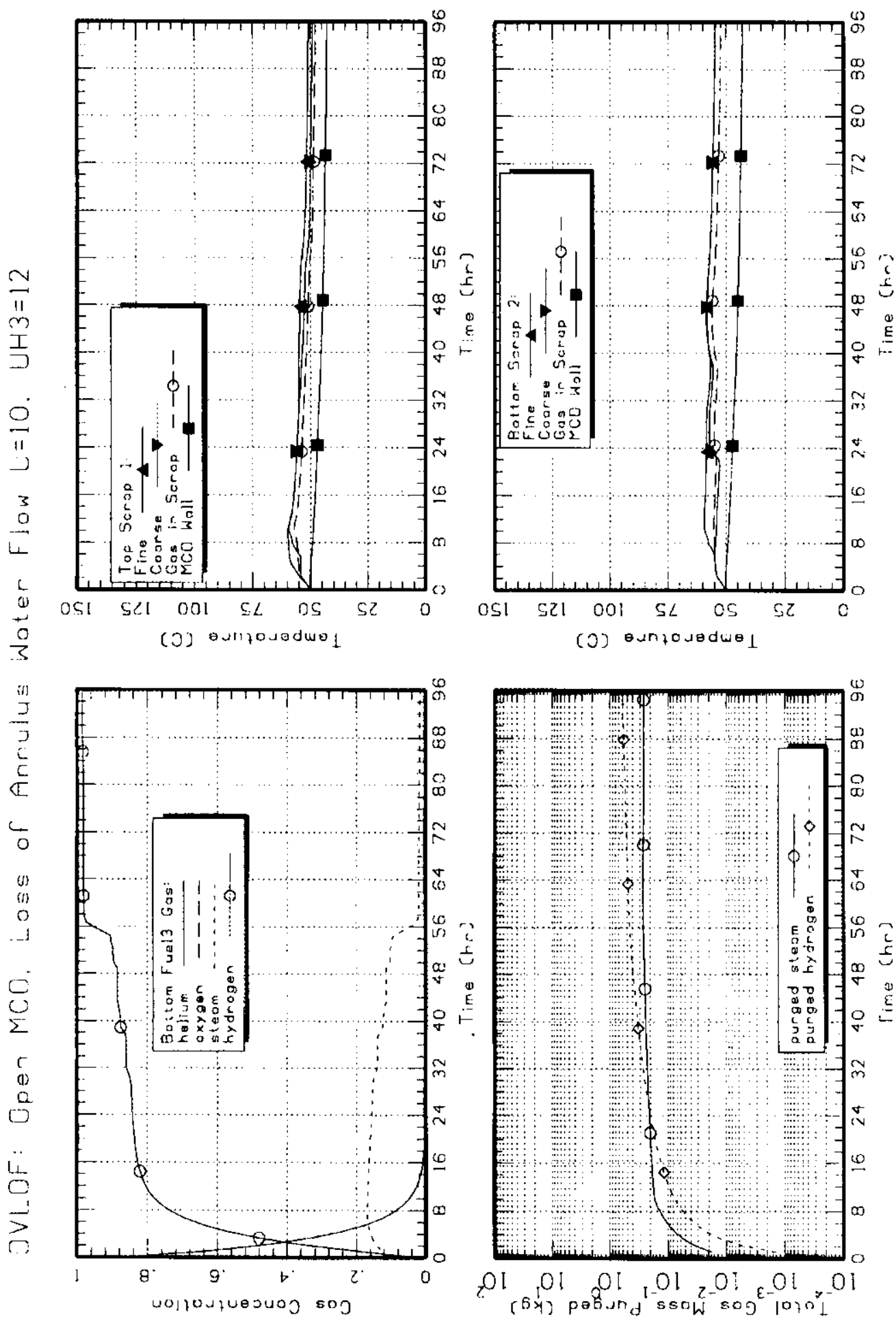
Figure 4. Key Output of Normal Case OVLOF with HANSF Code, Version 1.3.2. ( 3 of 3 sheets)

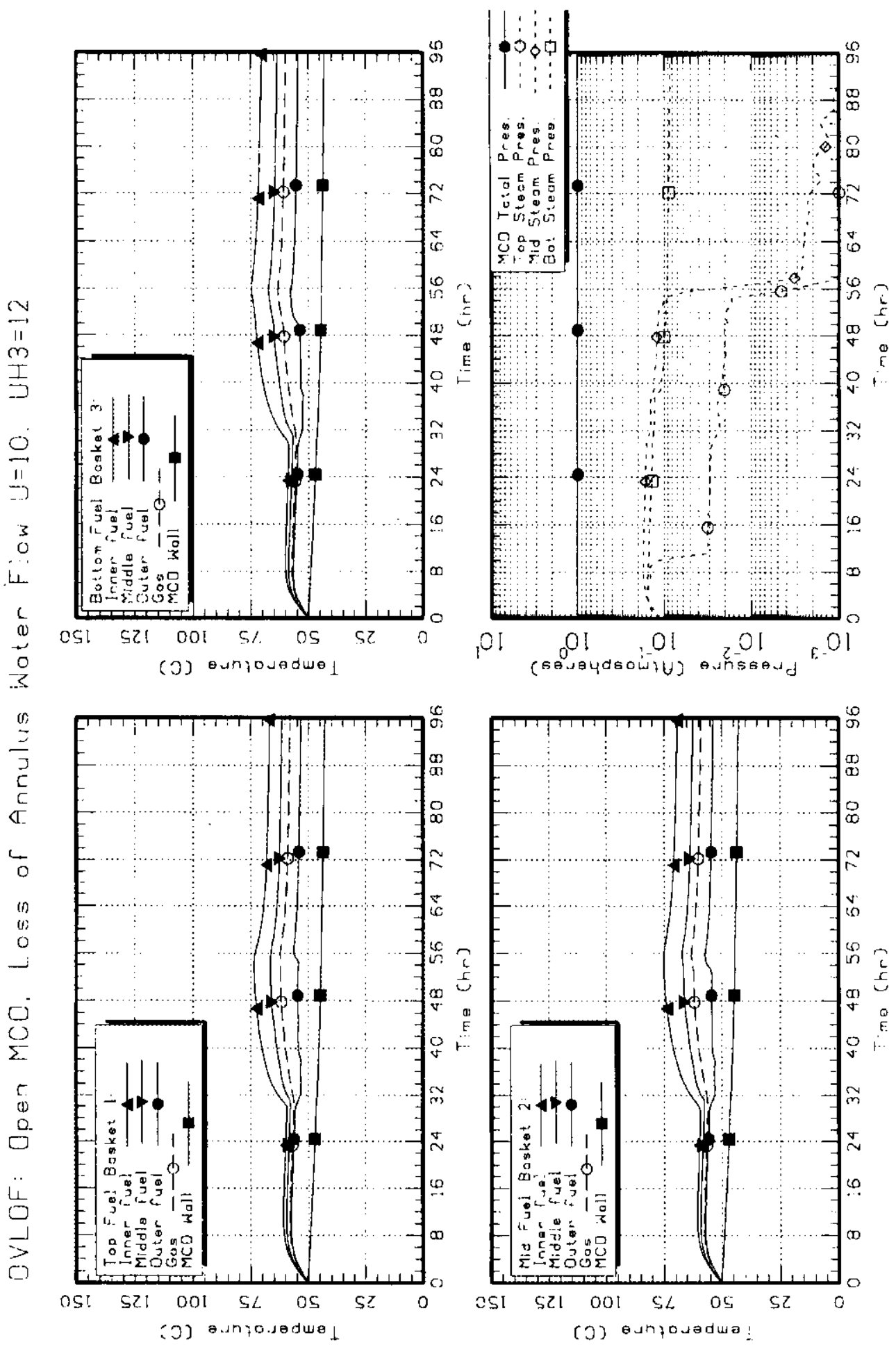


Figure 5. Key Output of Accident Case VXDGTAG with HANSFy Code. (1 of 3 sheets)
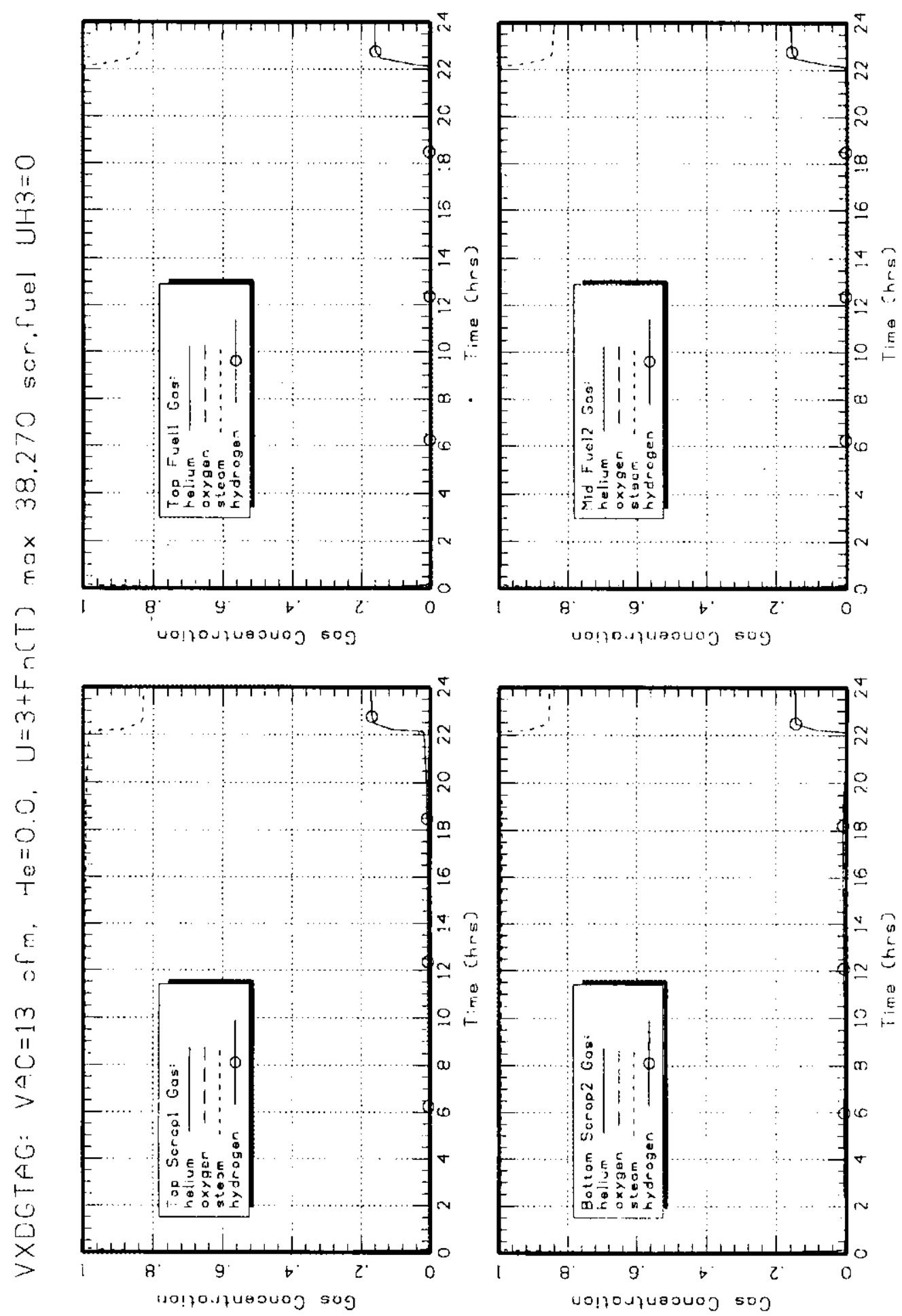
Figure 5. Key Output of Accident Case VXDGTAG with HANSFy Code. (2 of 3 sheets)
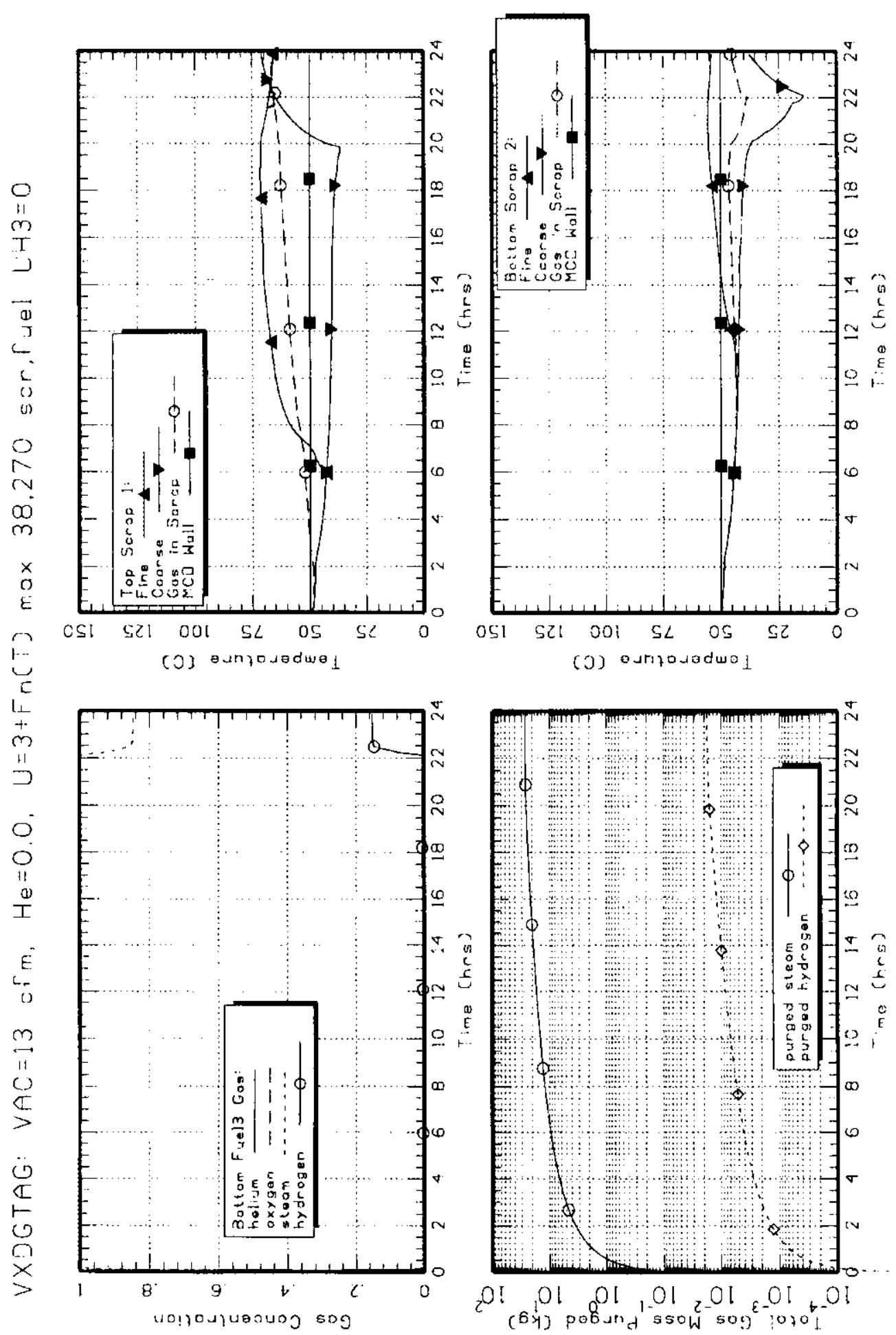
Figure 5. Key Output of Accident Case VXDGTAG with HANSFy Code. ( 3 of 3 sheets)

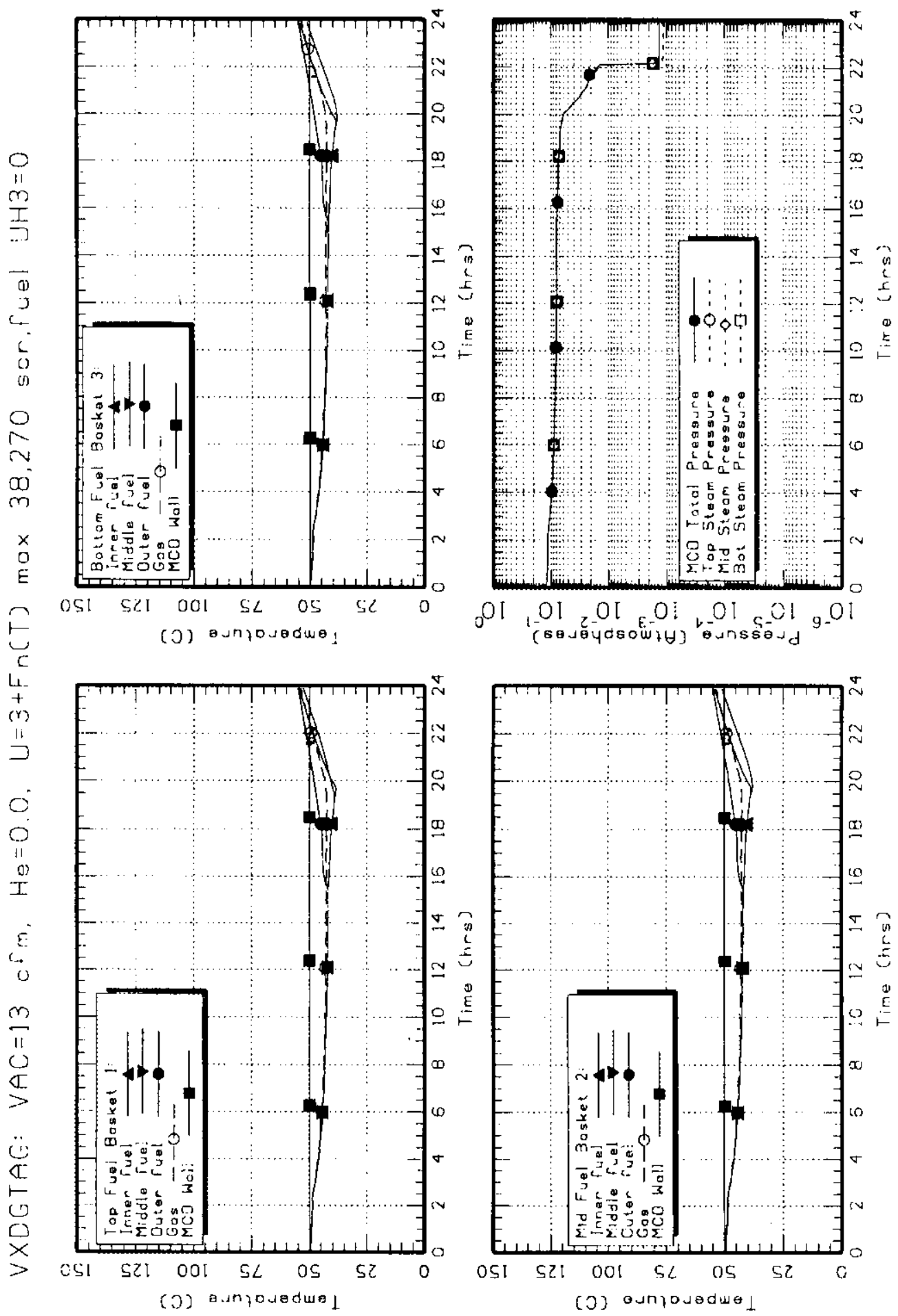


Figure 6. Key Output of Accident Case VXDG with HANSF Code, Version 1.3.2. ( 1 of 3 sheets)
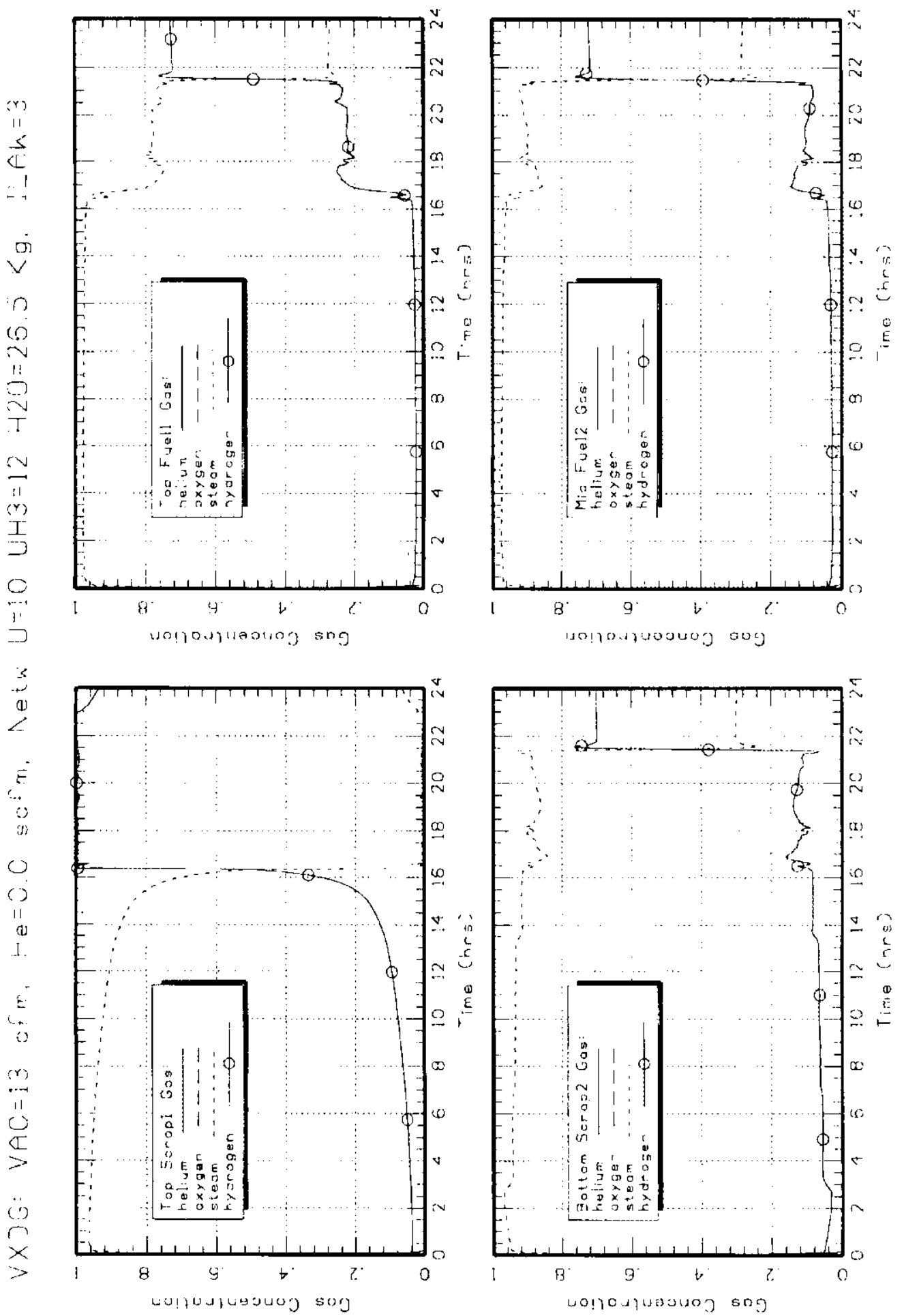
Figure 6. Key Output of Accident Case VXDG with HANSF Code, Version 1.3.2. ( 2 of 3 sheets)
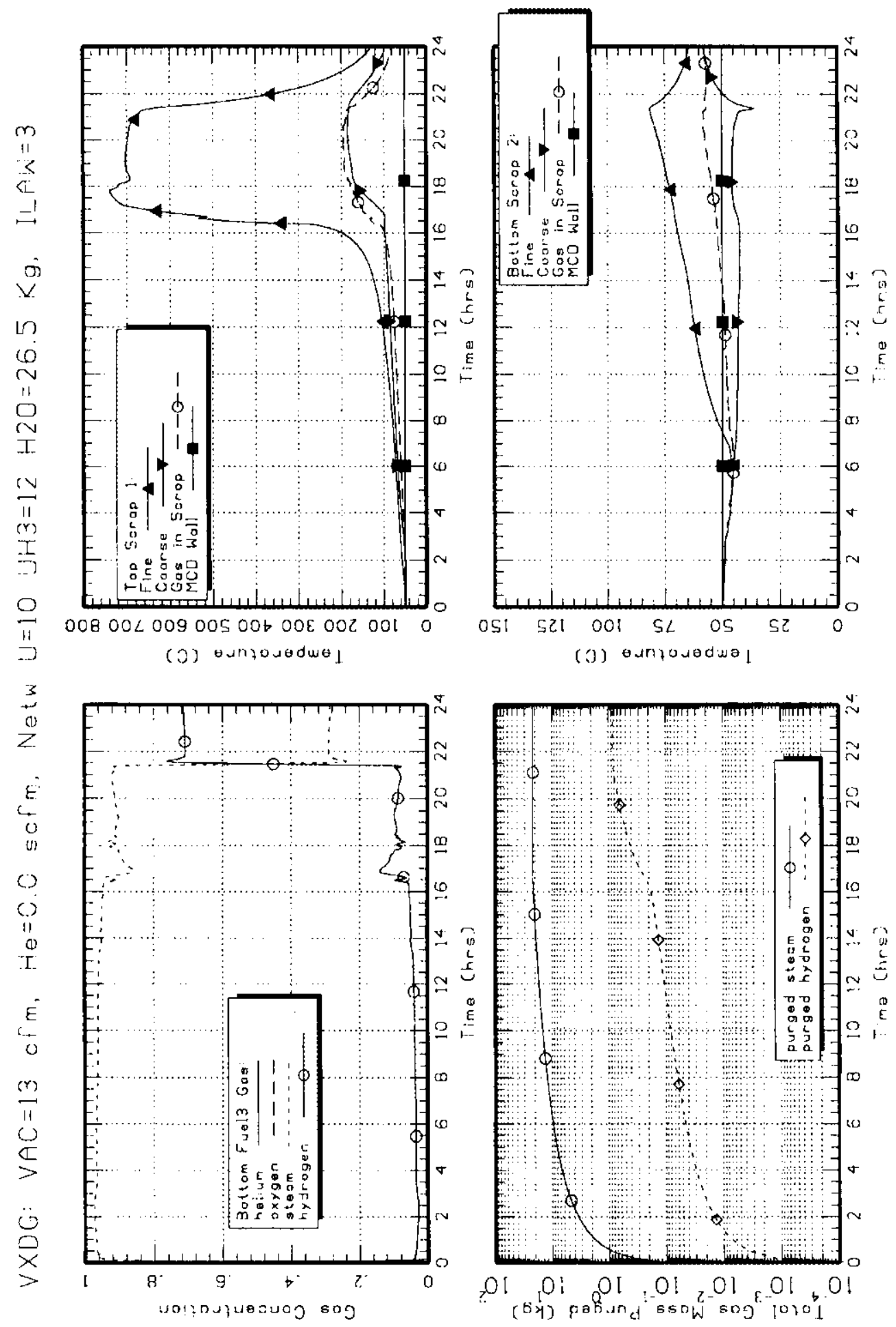
Figure 6. Key Output of Accident Case VXDG with HANSF Code, Version 1.3.2. ( 3 of 3 sheets)
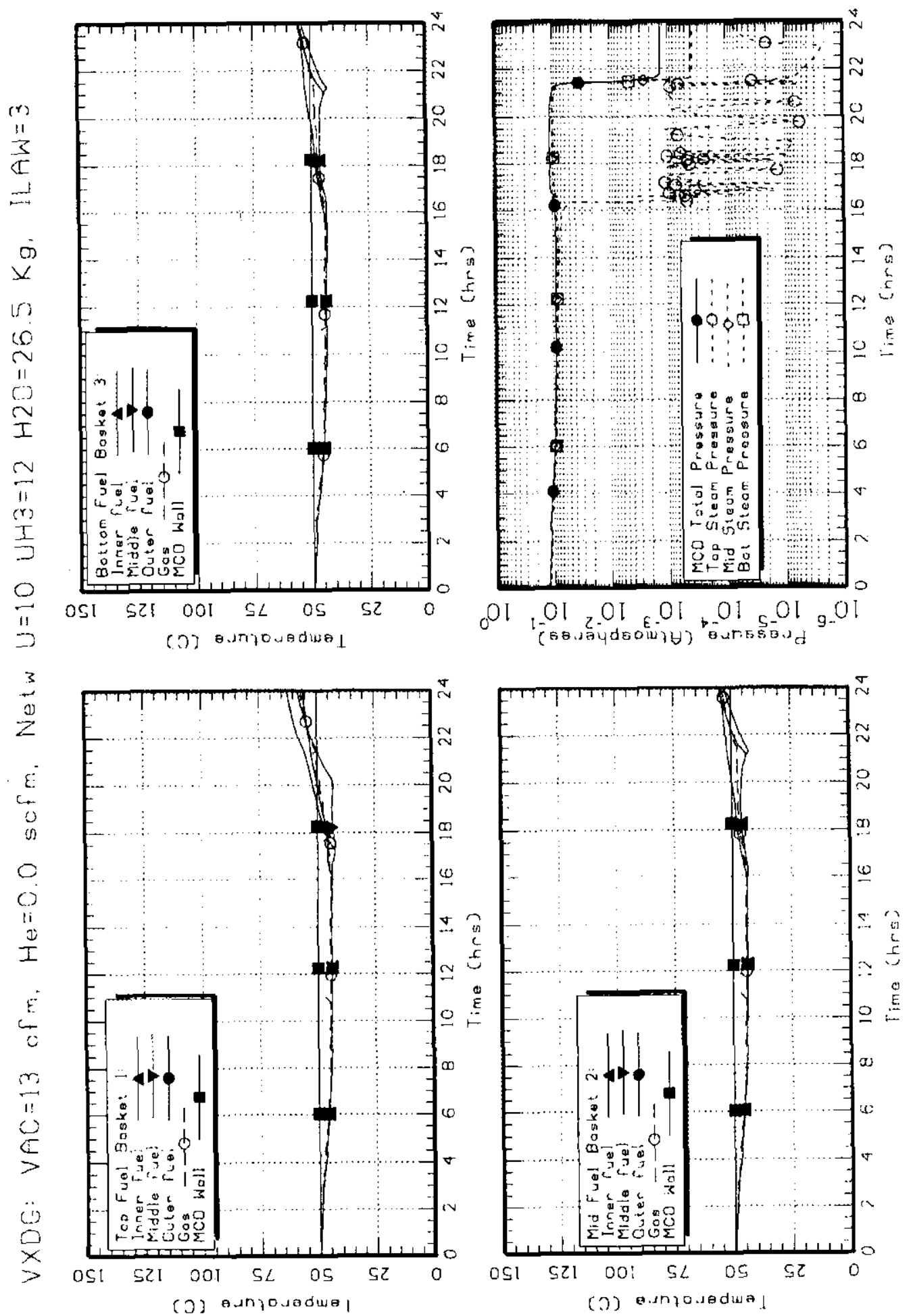
Figure 7. Key Output of Accident Case OVLOCTAG with HANSFy Code. ( 1 of 3 sheets)

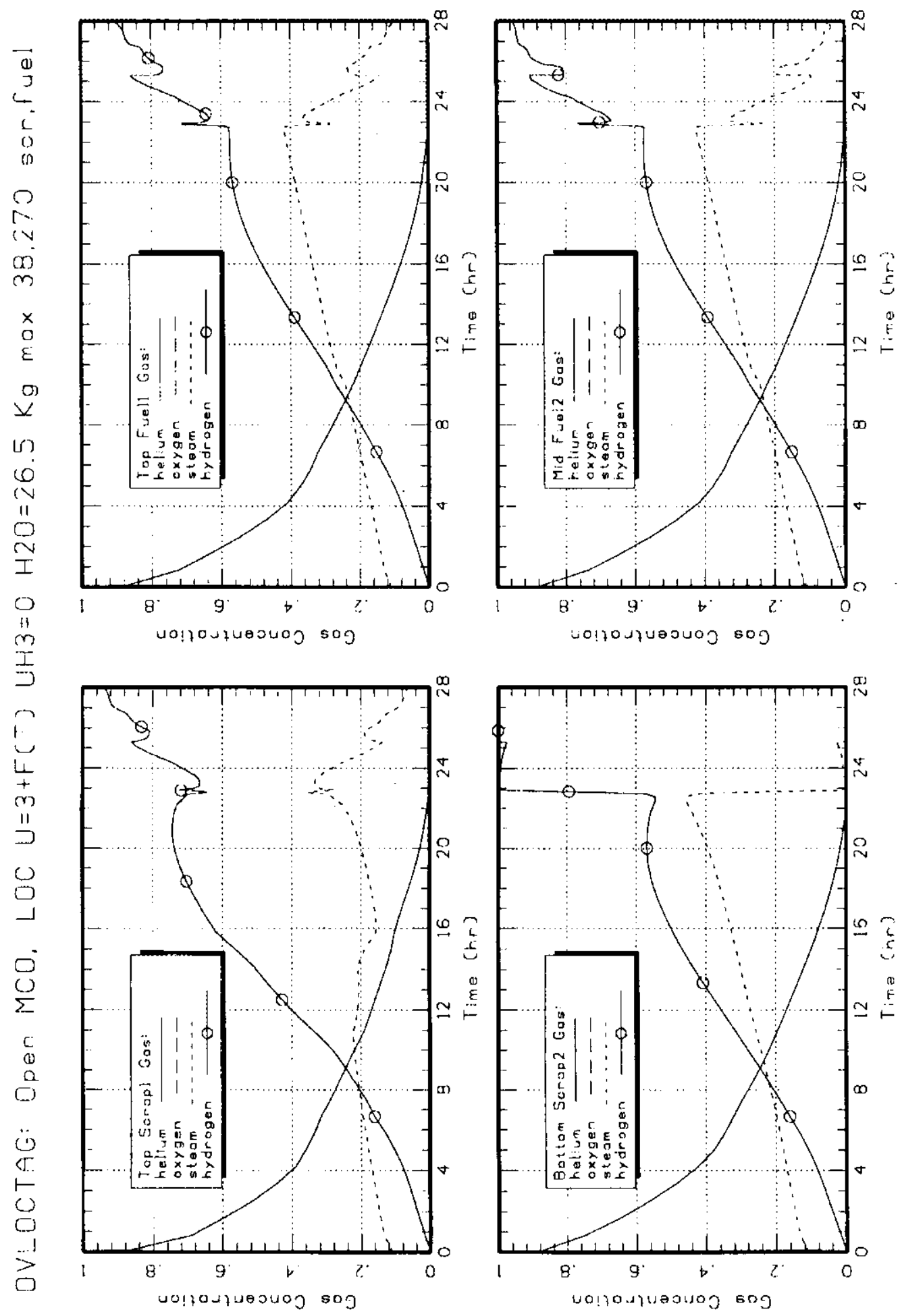


Figure 7. Key Output of Accident Case OVLOCTAG with HANSFy Code. ( 2 of 3 sheets)

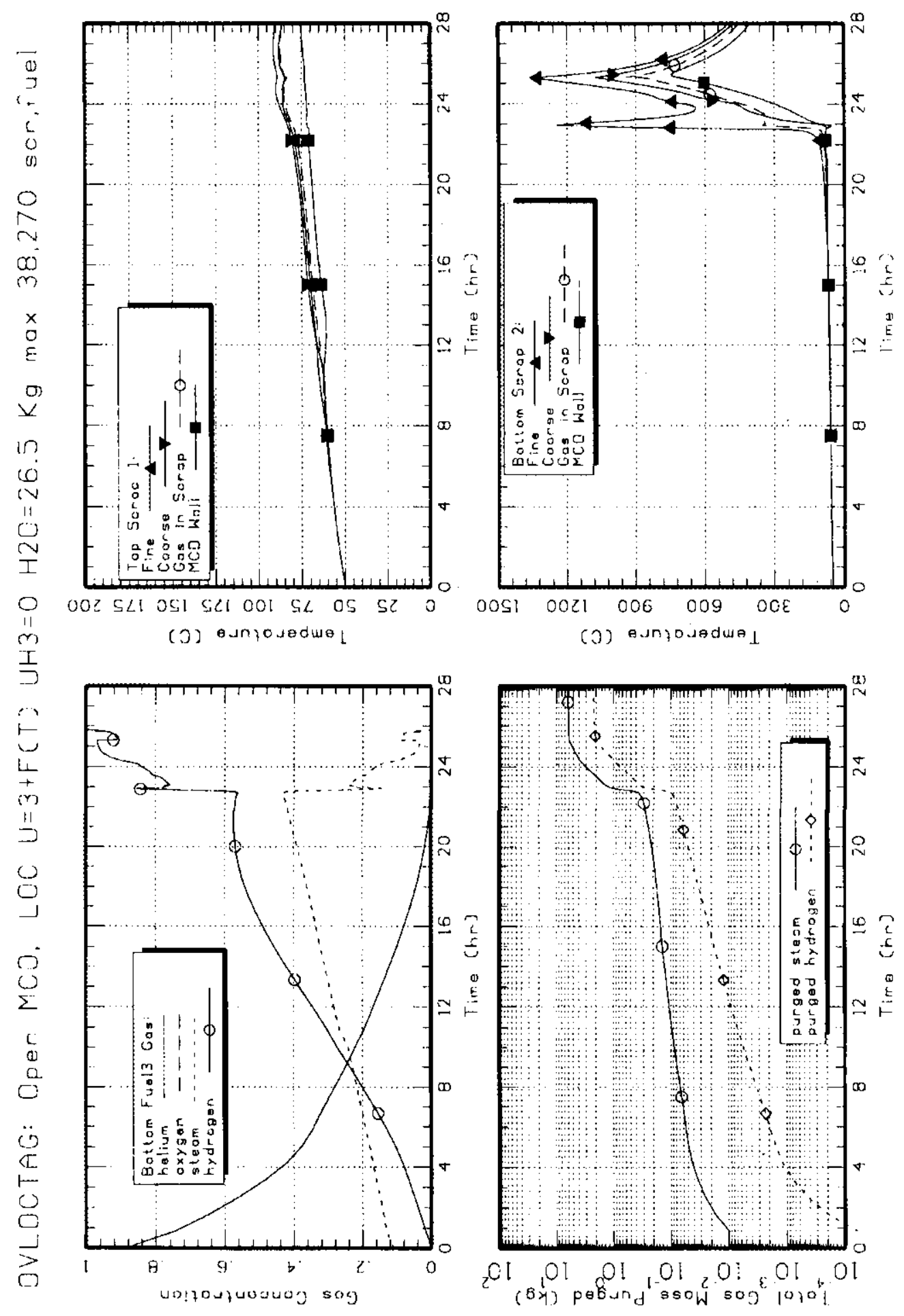


Figure 7. Key Output of Accident Case OVLOCTAG with HANSFy Code. ( 3 of 3 sheets)

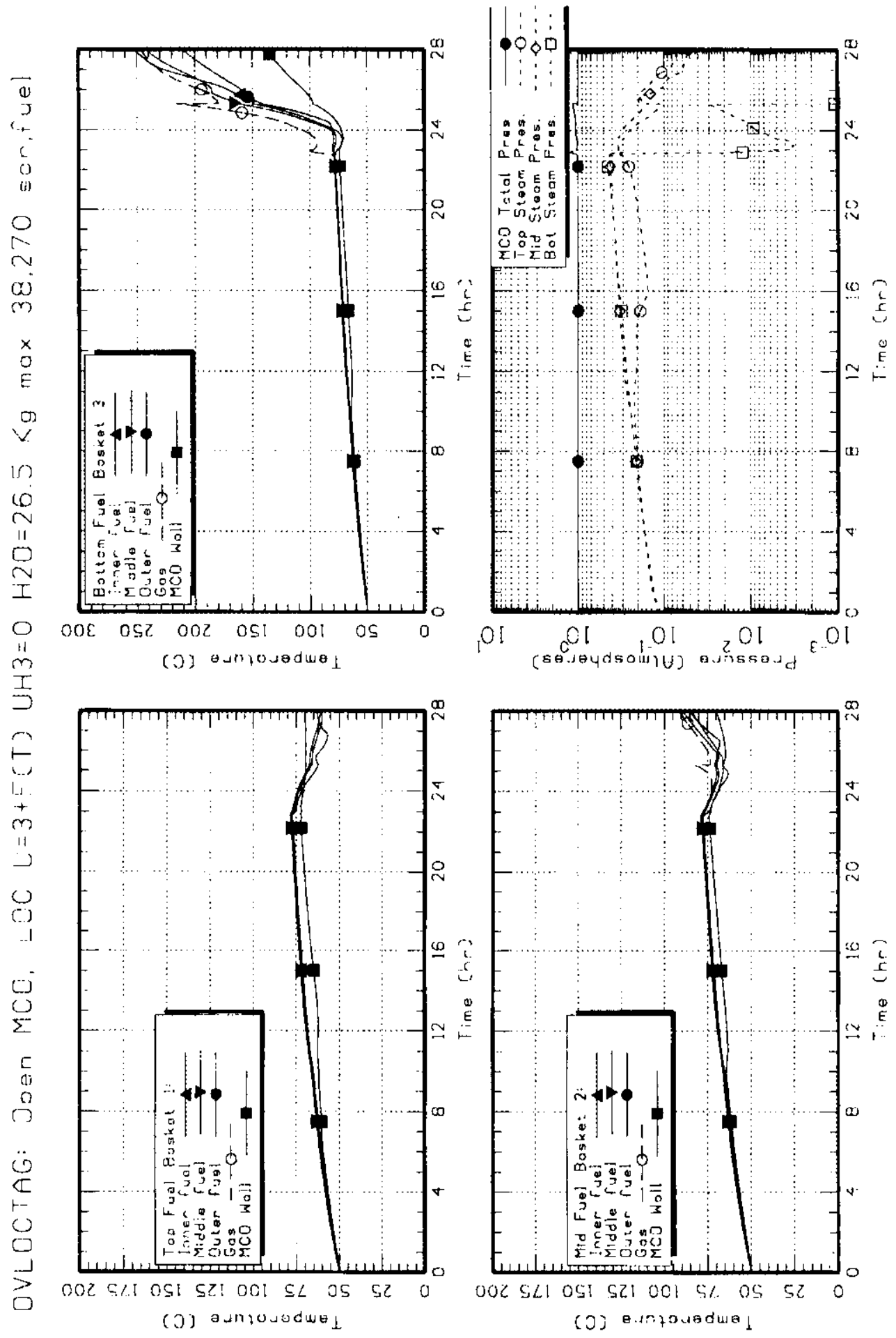


Figure 8. Key Output of Accident Case OVLOCXAL with HANSF Code, Version 1.3.2. ( 1 of 3 sheets)
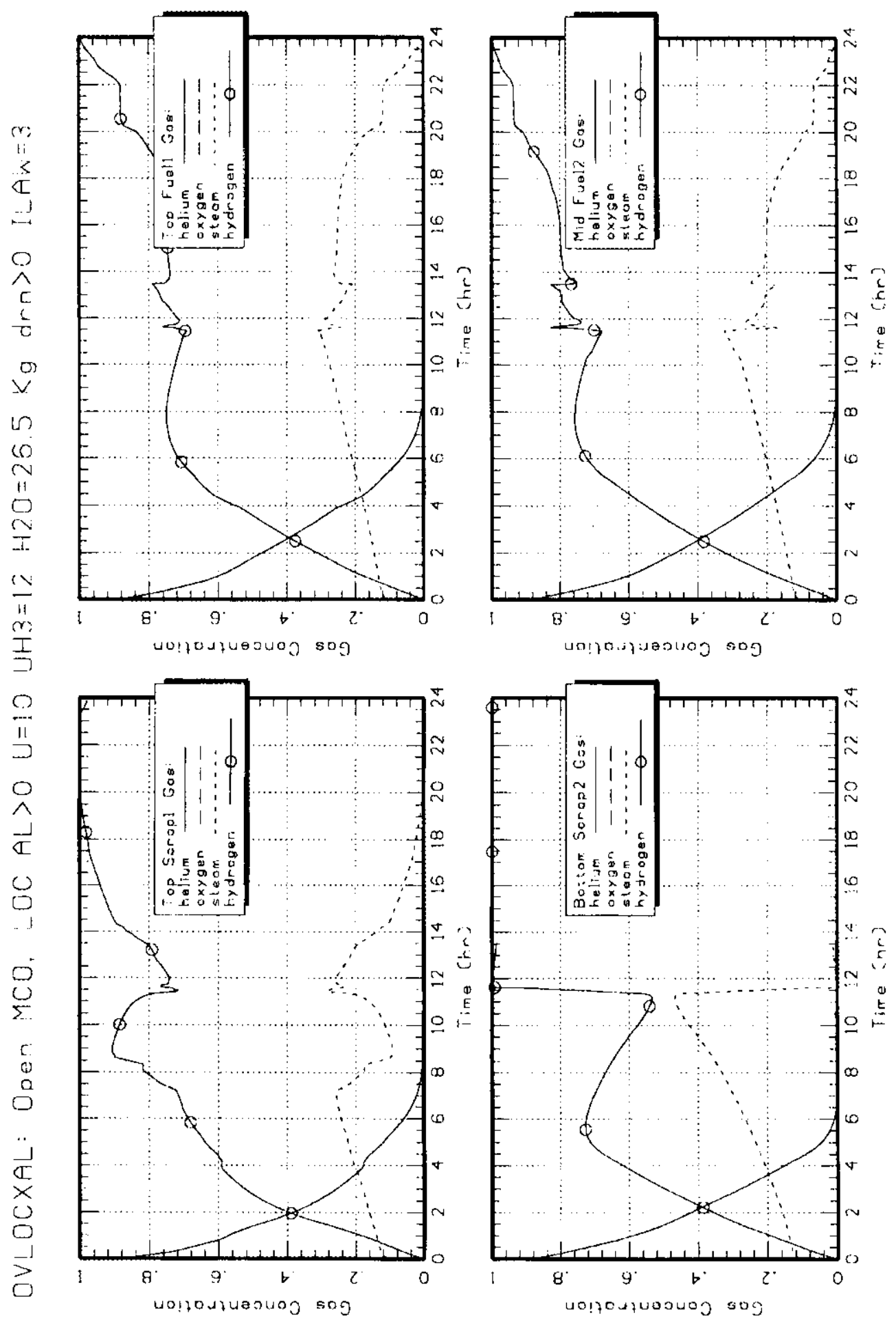
Figure 8. Key Output of Accident Case OVLOCXAL with HANSF Code, Version 1.3.2. ( 2 of 3 sheets)

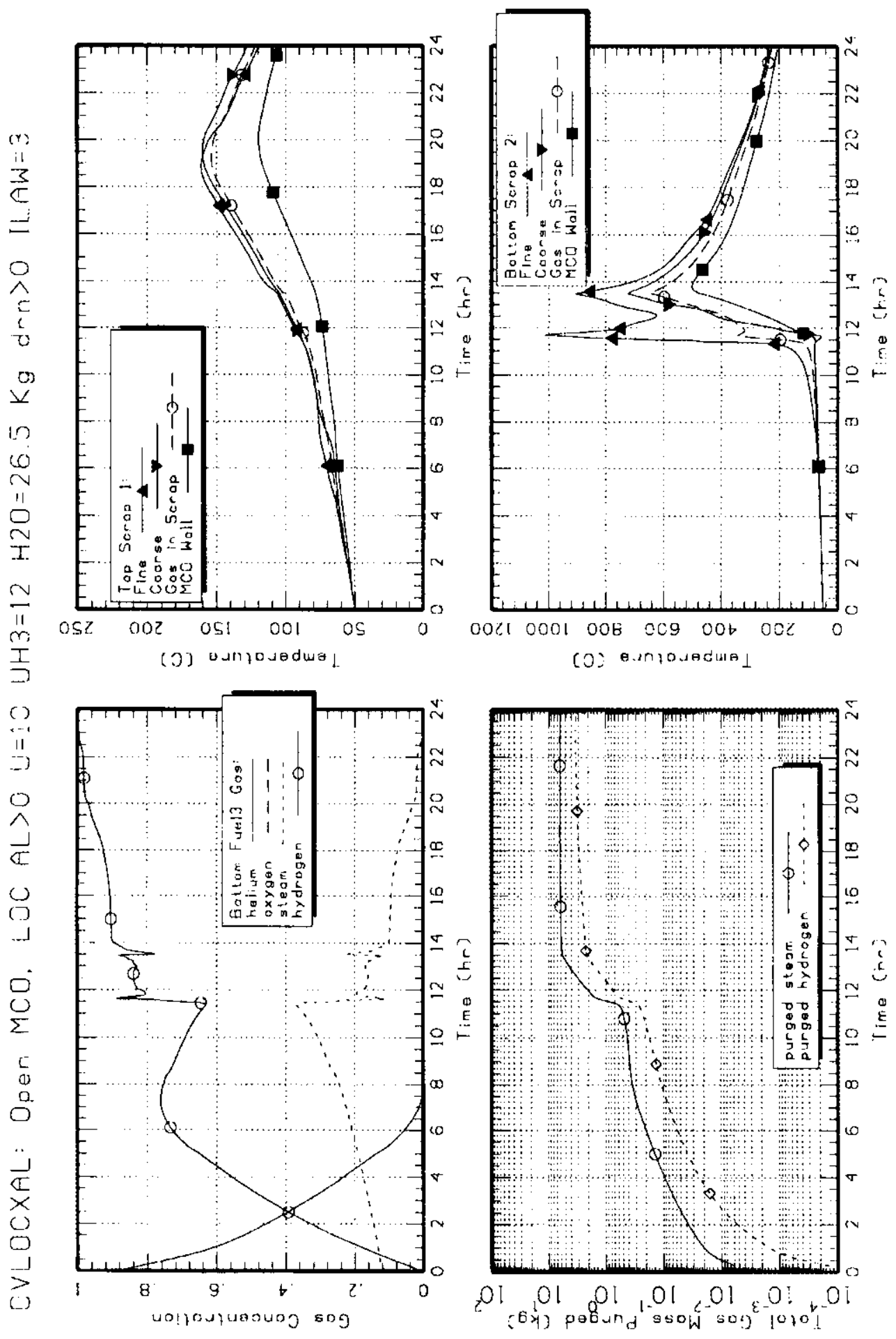


Figure 8. Key Output of Accident Case OVLOCXAL with HANSF Code, Version 1.3.2. ( 3 of 3 sheets)

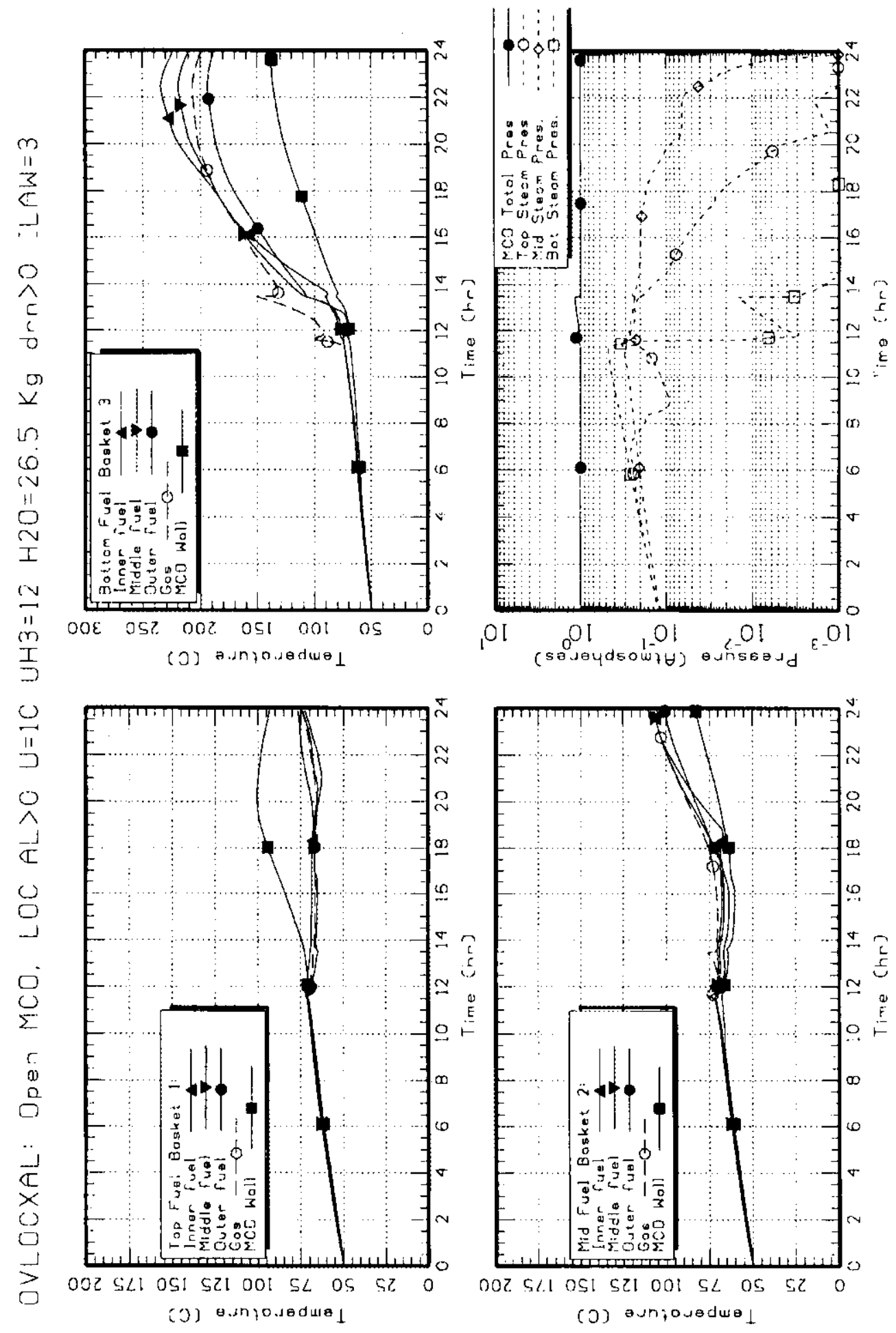


Figure 9. Key Output of Accident Case OVCALTAG with HANSFy Code and Calibrated Crumbling Model Input. (1 of 3 sheets)
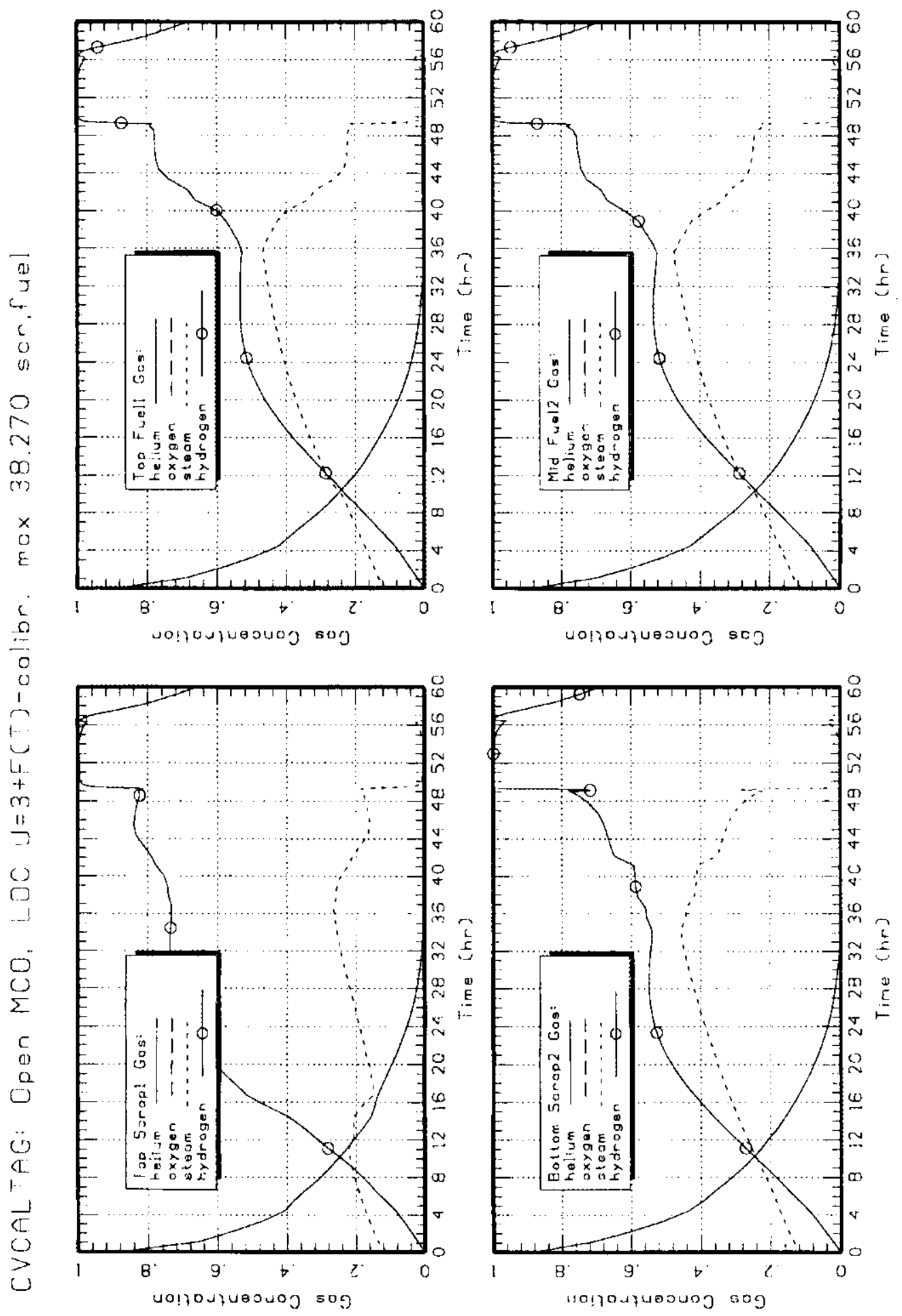
Figure 9. Key Output of Accident Case OVCALTAG with HANSFy Code and Calibrated Crumbling Model Input. (2 of 3 sheets)

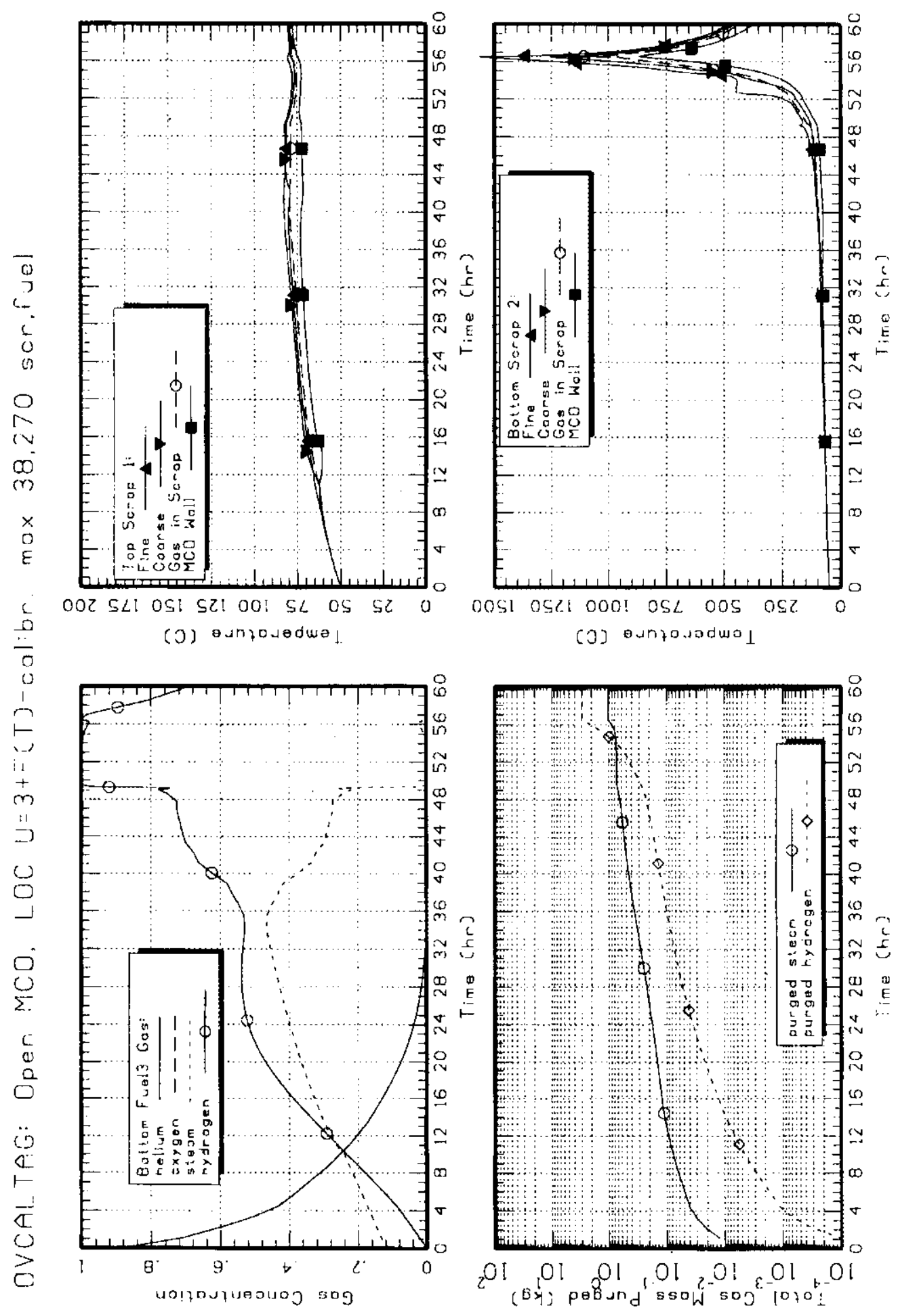


Figure 9. Key Output of Accident Case OVCALTAG with HANSFy Code and Calibrated Crumbling Model Input. ( 3 of 3 sheets)

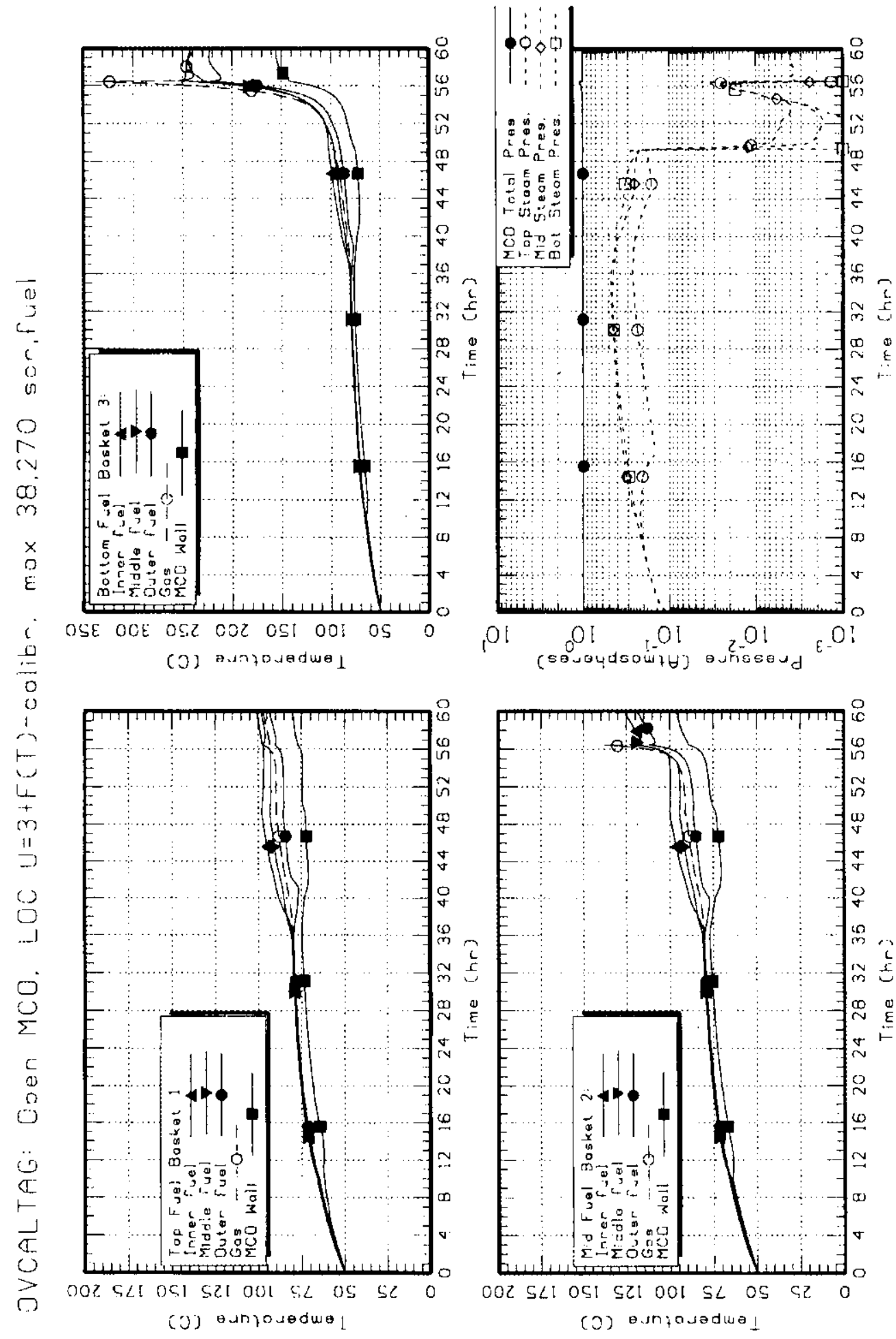


SNF-5698 REV 0

This page intentionally left blank. 


\section{APPENDIX A}

\section{DERIVATION OF TECHNICAL ASSISTANCE GROUP GROWTH RATE OF AREA DUE TO FUEL CRUMBLING}

This appendix was derived and written by A. Pajunen of the Spent Nuclear Fuel Project. The appendix represents the Spent Nuclear Fuel Project's interpretation of the Technical Assistance Group (TAG) fuel crumbling report, which contains the theory and basis for most of this appendix. The calibrated-TAG fuel crumbling model's area growth factor is also derived here and not in the TAG fuel crumbling report. The TAG surface area growth factor is incorporated in a time-dependent area growth model, which is finalized in Section 2.0 of the main report. 
SNF-5698 REV 0

This page intentionally left blank. 


\section{APPENDIX A}

\section{DERIVATION OF TECHNICAL ASSISTANCE GROUP GROWTH RATE OF AREA DUE TO FUEL CRUMBLING}

The rate of surface area growth is derived from Appendices 2 and 3 of Technical Assistance Group (TAG) Spent Nuclear Fuel (SNF) Crumbling Model and Recommendations on SNF Crumbling (Loscoe 1999). The rate of surface area growth per initial exposed area is expressed as follows .

$$
A_{\text {rate }}=\frac{d a}{d t}\left(\frac{A_{R}}{V_{R}}\right)
$$

where:

$$
\begin{aligned}
& A_{\text {rate }}=\text { surface area growth rate, } \frac{\mathrm{cm}^{2}}{\mathrm{hr}-\mathrm{cm}^{2} \text { geometric areal }} \\
& \frac{\mathrm{da}}{\mathrm{dt}}=\text { rubble front growth rate, } \mathrm{cm} / \mathrm{h} \\
& A_{R}=\text { rubble particle area, } \mathrm{cm}^{2} \\
& V_{R}=\text { rubble particle volume }, \mathrm{cm}^{3}
\end{aligned}
$$

Based on a spherical model of rubble,

$$
\begin{aligned}
& A_{R}=\pi D_{R}^{2} \\
& V_{R}=\frac{\pi}{6} D_{R}^{3}
\end{aligned}
$$

where:

$$
\mathrm{D}_{\mathrm{R}}=\text { rubble particle diameter, } \mathrm{cm}
$$

Therefore,

$$
A_{\text {rate }}=\frac{d a}{d t}\left(\frac{\pi D_{R}^{2}}{\pi / 6 D_{R}^{3}}\right)=\left(\frac{6}{D_{R}}\right) \frac{d a}{d t}
$$


The rubble front growth rate is defined by Loscoe (1999) in Appendices 2 and 3, resulting in the following.

$$
\frac{\mathrm{da}}{\mathrm{dt}}=\frac{4 \xi_{\mathrm{p}} \mathrm{R}_{\mathrm{U}}}{\left(\rho_{\mathrm{U}}-\rho_{\mathrm{O} \mathrm{x}}\right)(1000)} \frac{\left(\frac{\mathrm{a}}{2}+\mathrm{CTOD}\right)}{\text { CTOD }}
$$

where:

$$
\begin{aligned}
& \xi_{\mathrm{O}}=\text { parabolic reaction rate factor, dimensionless } \\
& \mathrm{R}_{\mathrm{U}}=\text { uranium reaction rate, } \mathrm{mg} \mathrm{U} / \mathrm{cm}^{2}-\mathrm{h} \\
& \rho_{\mathrm{U}}=\text { density of uranium metal, } \mathrm{g} / \mathrm{cm}^{3} \\
& \rho_{O \mathrm{x}}=\text { density of uranium oxide, } \mathrm{g} / \mathrm{cm}^{3} \\
& \mathrm{a}=\text { cell diameter, } \mathrm{cm} \\
& \text { CTOD }=\text { crack tip opening displacement, } \mathrm{cm}
\end{aligned}
$$

This results in an overall area growth rate estimate as follows.

$$
\Lambda_{\text {rate }}=\frac{24 \xi_{p} R_{U}}{D_{R}\left(\rho_{U}-\rho_{O x}\right)(1000)} \frac{\left(\frac{a}{2}+\text { CTOD }\right)}{\text { CTOD }}
$$

For the oxygen free water vapor system, Loscoe (1999) uses the following uranium reaction rate correlation, which is equivalent to that used in HNF-SD-SNF-TI-015, Spent Nuclear Fuel Project Technical Databook, modified to a mass of uranium reacted basis assuming the reaction stoichiometry produces $\mathrm{UO}_{2}$.

$$
\begin{aligned}
\mathrm{R}_{\mathrm{U}} & =\sqrt{\mathrm{P}_{\mathrm{H} 20}}\left(2.14 \times 10^{4}\right) \exp \left(-\frac{4937}{\mathrm{~T}}\right)\left(\frac{238}{32}\right) \\
& =\left(1.59 \times 10^{5}\right) \sqrt{\mathrm{P}_{\mathrm{H} 2 \mathrm{O}}} \exp \left(-\frac{4937}{\mathrm{~T}}\right) \frac{\mathrm{mgU}}{\mathrm{hr}-\mathrm{cm}^{2}}
\end{aligned}
$$

where:

$$
\begin{aligned}
& P_{\mathrm{H} 2 \mathrm{O}}=\text { partial pressure water vapor, } \mathrm{kPa} \\
& \mathrm{T}=\text { absolute temperature, } \mathrm{K}
\end{aligned}
$$


The area growth rate equation is developed assuming base case parameters from Table 1 of Loscoe (1999) such that:

$$
\begin{aligned}
& a=2.54 \times 10^{-3} \mathrm{~cm} \\
& \mathrm{CTOD}=1.27 \frac{\mathrm{K}_{\mathrm{R}}^{2}(100)}{\mathrm{E} \sigma_{\mathrm{y}}} \\
& =1.27 \frac{(50 / 2 \mathrm{MPa} \sqrt{\mathrm{m}})^{2}(100 \mathrm{~cm} / \mathrm{m})}{\left(1.793 \times 10^{5} \mathrm{MPa}\right)(534 \mathrm{MPa})} \\
& =8.29 \times 10^{-4} \mathrm{~cm} \\
& \rho_{U}=19 \mathrm{~g} / \mathrm{cm}^{3} \\
& \rho_{O \mathrm{x}}=11 \mathrm{~g} / \mathrm{cm}^{3} \\
& \xi_{p}=10 \\
& \mathrm{D}_{\mathrm{R}}=0.2 \mathrm{~cm} \\
& \begin{aligned}
A_{\text {rate }} & =\frac{24(10)\left(1.59 \times 10^{5}\right) \sqrt{\mathrm{P}_{\mathrm{H} 20}} \exp \left(-\frac{4937}{\mathrm{~T}}\right)}{(0.2)(19-11)(1000)} \frac{\left(\frac{2.54 \times 10^{-3}}{2}+8.29 \times 10^{-4}\right)}{\left(8.29 \times 10^{-4}\right)} \\
& =\left(6.04 \times 10^{4}\right) \sqrt{\mathrm{P}_{1220}} \exp \left(-\frac{4937}{\mathrm{~T}}\right)
\end{aligned}
\end{aligned}
$$

Equation (6) provides an estimate of the fractional surface area growth rate that varies with MCO operating conditions. Based on the model in Loscoe (1999), the area of a fuel reaction surface in the $\mathrm{MCO}$ is bounded by the following equation:

$$
\begin{aligned}
A(t) & =A_{g}+A_{\text {rate }} t A_{g} \\
& =A_{g}\left(1+A_{\text {rate }} t\right)
\end{aligned}
$$

where:

$A(t)=$ the time dependent surface area, $\mathrm{cm}^{2}$ or $\mathrm{m}^{2}$

$\mathrm{A}_{\mathrm{g}}=$ initial geometric surface area, $\mathrm{cm}^{2}$ or $\mathrm{m}^{2}$

$\mathrm{t}=$ time that fuel has been crumbling, $\mathrm{h}$

$A_{\text {rate }}=$ surface reaction area fractional growth rate due to crumbling (Equation 6 ), $1 / \mathrm{h}$

Equation (7) provides an upper bound to reaction surface area for scenarios with increasing fuel temperatures. Since $A_{\text {rate }}$ increases monotonically with increasing fuel temperatures, the term 
$\left(A_{\text {rate }} t\right)$ in Equation (7) bounds the exact term which is the integral of $A_{\text {rate }}$ with respect to time. In other words,

$$
\begin{aligned}
A_{\text {rate }}(t) \times t= & \sum_{i} A_{\text {rate }}(t) \times\left(t_{i}-t_{i-1}\right) \\
& \geq \sum_{i} A_{\text {rate }}\left(t_{i}\right) \times\left(t_{i}-t_{i-1}\right) \text { if } A_{\text {rate }}(t) \geq A_{\text {rate }}(t i) \text { for all } t_{i}<t \\
& \geq \int_{A_{\text {rate }} d t,}
\end{aligned}
$$

which is the case for increasing fuel temperature scenarios up to the first fuel temperature peak. The first fuel peak temperature is the main one of interest. However, after the peak temperature is reached, the growth rate will most likely be at its upper bound (Section 2.1), making Equation (7) also bounding for all high temperature scenarios. Thus, Equation (7), with its upper bound (Section 2.1), is conservative for representing the time-dependent reaction surface area for increasing or high temperature scenarios.

An attempt was made to calibrate the model presented in Loscoe (1999) to observations from TGA experiments in moist helium. Equations (8) and (9) indicate the relationships from Loscoe (1999) for incubation time and sample rubblization time. Figure 1 shows that incubation time observations are approximated if the cell size (a) is estimated at $0.0287 \mathrm{~cm}$ and the initial crack tip opening displacement $\left(\mathrm{CTOD}_{\mathrm{i}}\right)$ is estimated at $0.06 \mathrm{~cm}$. Figure 2 indicates that sample rubblization time predictions are approximated if these modified parameters are combined with a crack tip opening displacement (CTOD) of $0.015 \mathrm{~cm}$ and eliminating the assumption of parabolic reaction rate enhancement during sample rubblization.

$$
\begin{gathered}
\mathrm{T}_{\text {inc }}=\frac{\left(\rho_{\mathrm{U}}-\rho_{\mathrm{OX}}\right)(1000)}{4 \xi_{\mathrm{i}} \mathrm{R}_{\mathrm{U}}} \frac{\mathrm{aCTOD}}{\left(\mathrm{a} / 2+\mathrm{CTOD}_{\mathrm{i}}\right)} \\
\mathrm{T}_{\text {rubble }}=\frac{\left(\rho_{\mathrm{U}}-\rho_{(\mathrm{)})}\right)(1000)}{4 \mathrm{R}_{\mathrm{U}}}\left(\frac{\mathrm{a} \mathrm{CTOD}_{\mathrm{i}}}{\xi_{\mathrm{i}}\left(\mathrm{a} / 2+\mathrm{CTOD}_{\mathrm{i}}\right)}+\frac{\left.\left(\mathrm{t}_{1 / 2}-\mathrm{a}\right) \mathrm{fCTOD}\right)}{\xi_{\mathrm{p}}(\mathrm{a} / 2+\mathrm{CTOD})}\right)
\end{gathered}
$$

where:

$$
\begin{aligned}
& \xi_{i}=\text { linear reaction rate factor, dimensionless } \\
& \text { CTOD }_{i}=\text { initial crack tip opening displacement, } \mathrm{cm} \\
& \mathrm{t}_{1 / 2}=\text { half thickness of TGA sample, } \mathrm{cm} \\
& \mathrm{f}=\text { fraction of TGA sample rubblized, dimensionless } \\
& \mathrm{T}_{\text {inc }}=\text { rubble incubation time, } \mathrm{h} \\
& \mathrm{T}_{\text {rubble }}=\text { time to rubblize a fraction of the sample, } \mathrm{h}
\end{aligned}
$$


The rate of area growth estimated in Equation (6) was recalculated based on the parameters calibrated to the TGA sample observations. The modified area growth rate equation is shown as follows:

$$
\begin{aligned}
& \mathrm{a}=0.0287 \mathrm{~cm} \\
& \text { CTOD }=0.015 \mathrm{~cm} \\
& \rho_{U}=19 \mathrm{~g} / \mathrm{cm}^{3} \\
& \rho_{O \mathrm{x}}=10.96 \mathrm{~g} / \mathrm{cm}^{3} \\
& \xi_{\mathrm{O}}=1 \\
& D_{\mathrm{R}}=0.2 \mathrm{~cm}
\end{aligned}
$$

$$
\begin{aligned}
A_{\text {rate }} & =\frac{24(1)\left(1.59 \times 10^{5}\right) \sqrt{\mathrm{P}_{\mathrm{H} 20}} \exp \left(-\frac{4937}{\mathrm{~T}}\right)}{(0.2)(19-11)(1000)} \frac{\left(\frac{0.0287}{2}+0.015\right)}{(0.015)} \\
& =\left(4.67 \times 10^{3}\right) \sqrt{\mathrm{P}_{\mathrm{H} 20}} \exp \left(-\frac{4937}{\mathrm{~T}}\right)
\end{aligned}
$$

The area growth rate estimate in Equation (10) provides an alternative that is used in Equation (7).

\section{REFERENCES}

HNF-SD-SNF-TI-015, 1998, Spent Nuclear Fuel Project Technical Databook, Rev. 6, Fluor Daniel Hanford, Incorporated, Richland, Washington.

Loscoe, P. G., 1999, Contract No. DE-AC06-96RL13200 - Technical Assistance Group (TAG) Spent Nuclear Fuel (SNF) Crumbling Model and Recommendations on SNF Crumbling (Letter 00-SFO-034 to R. D. Hanson, Fluor Daniel Hanford, Incorporated, November 19), U.S. Department of Energy, Richland Operations Office, Richland, Washington. 
SNF-5698 REV 0

This page intentionally left blank. 
Figure 1. Comparison of Calibrated Model Incubation Time Predictions with Observations.

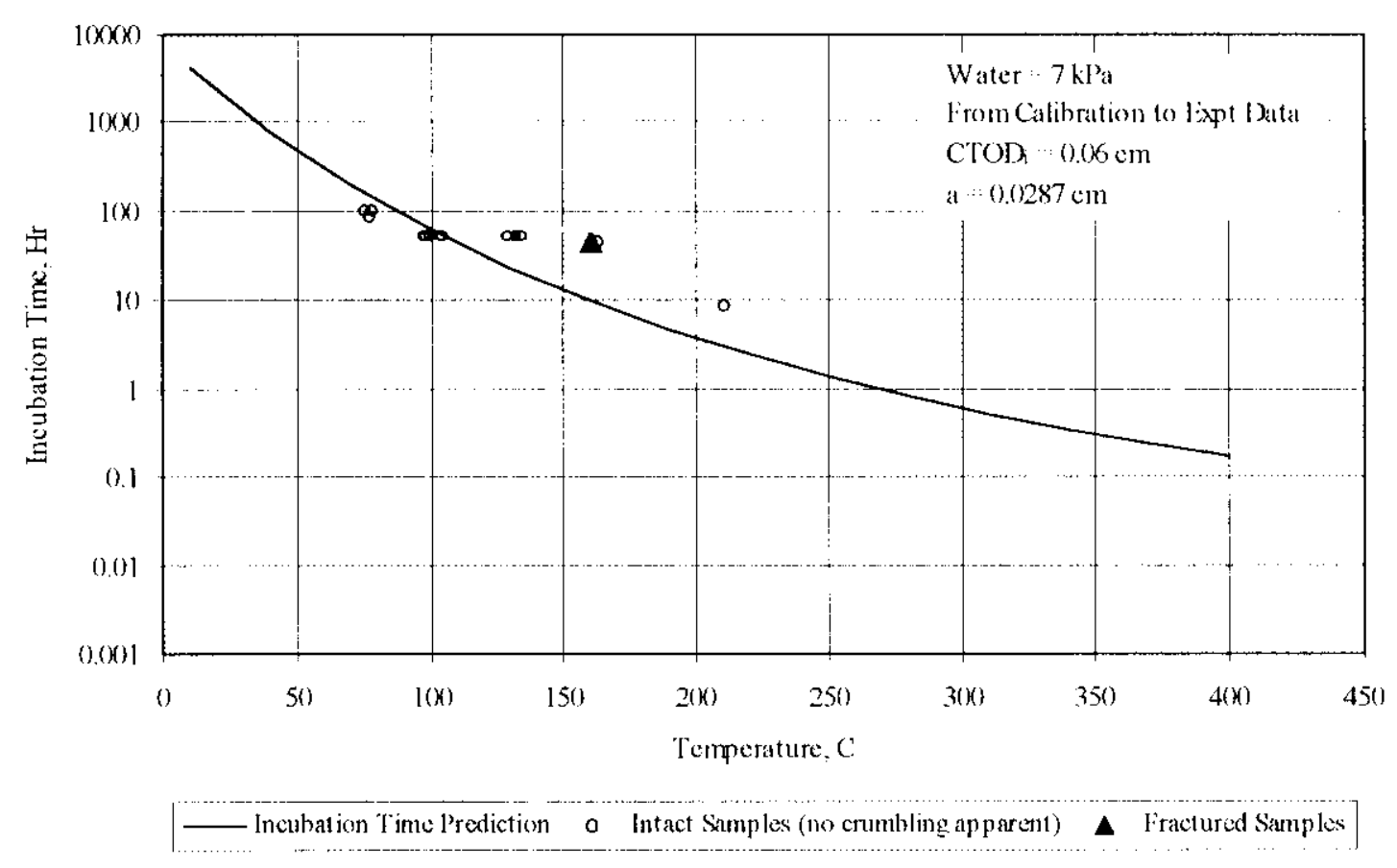


Figure 2. Comparison of Calibrated Model Sample Rubble Time Predictions with Observations.

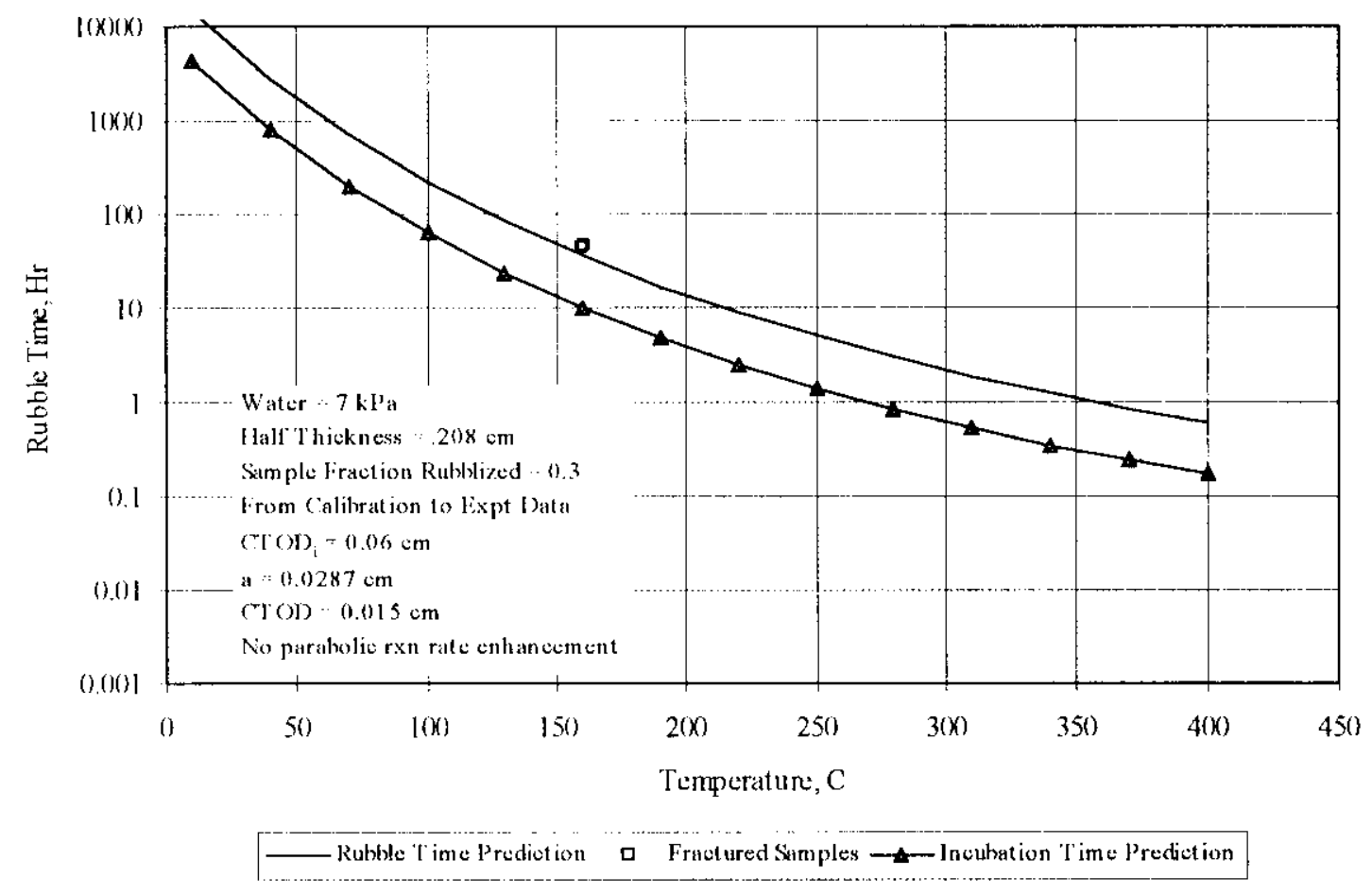


SNF-5698 REV 0

\section{APPENDIX B}

CODE CHANGES TO HANSF FOR TECHNICAL ASSISTANCE GROUP FUEL CRUMBLING MODEL 
SNF-5698 REV 0

This page intentionally left blank 


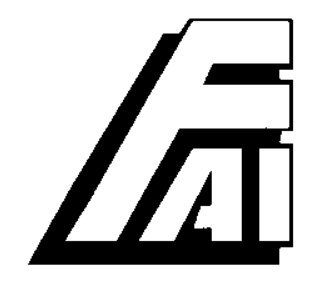

Fauske \& Associates, Inc.

DATE: January 14,2000

TO: Melvin G. Piepho

CC: Darrel R. Duncan, Martin G. Plys

FROM: $\quad$ Sung Jin Lee

\section{SUBJECT: Release of HANSFy Code, A Derivative of HANSF 1.3.2}

Per your request the HANSFy code, a derivative of HANSF 1.3.2 code, was issued on December 14, 1999. It attempted to incorporate the effective rate multiplier due to fuel crumbling. According to the fuel crumbling model you have prescribed, the time-dependant reaction area has the form

$$
A_{\text {reaction }}=A_{\text {germetric }}\left[3+t \sqrt{\frac{P_{s t}}{1000 P^{\prime} a}} \quad a 10^{b / 7}\right]
$$

where

$$
\begin{array}{ll}
t & \text { is time in seconds, } \\
P_{s t} & \text { is steam partial pressure, } \\
T & \text { is fuel temperature in Kelvin, and } \\
a, b & \text { are user input parameters (FOX or FOXSC) }
\end{array}
$$

The multiplier, $\left(\frac{A_{\text {eeacton }}}{A_{\text {germetry }}}\right)$, is further limited to 270 for fuel elements and 38 for scrap.

The difference listing of the code change is attached. It should be noted that this derivative code has not been QAed and will not be incorporated in future versions of HANSF code. 
SNF-5698 REV 0

ATTACHMENT

Difference Listing Between HANSFy and HANSF 1.3.2 Code 


\section{SNF-5698 REV 0}

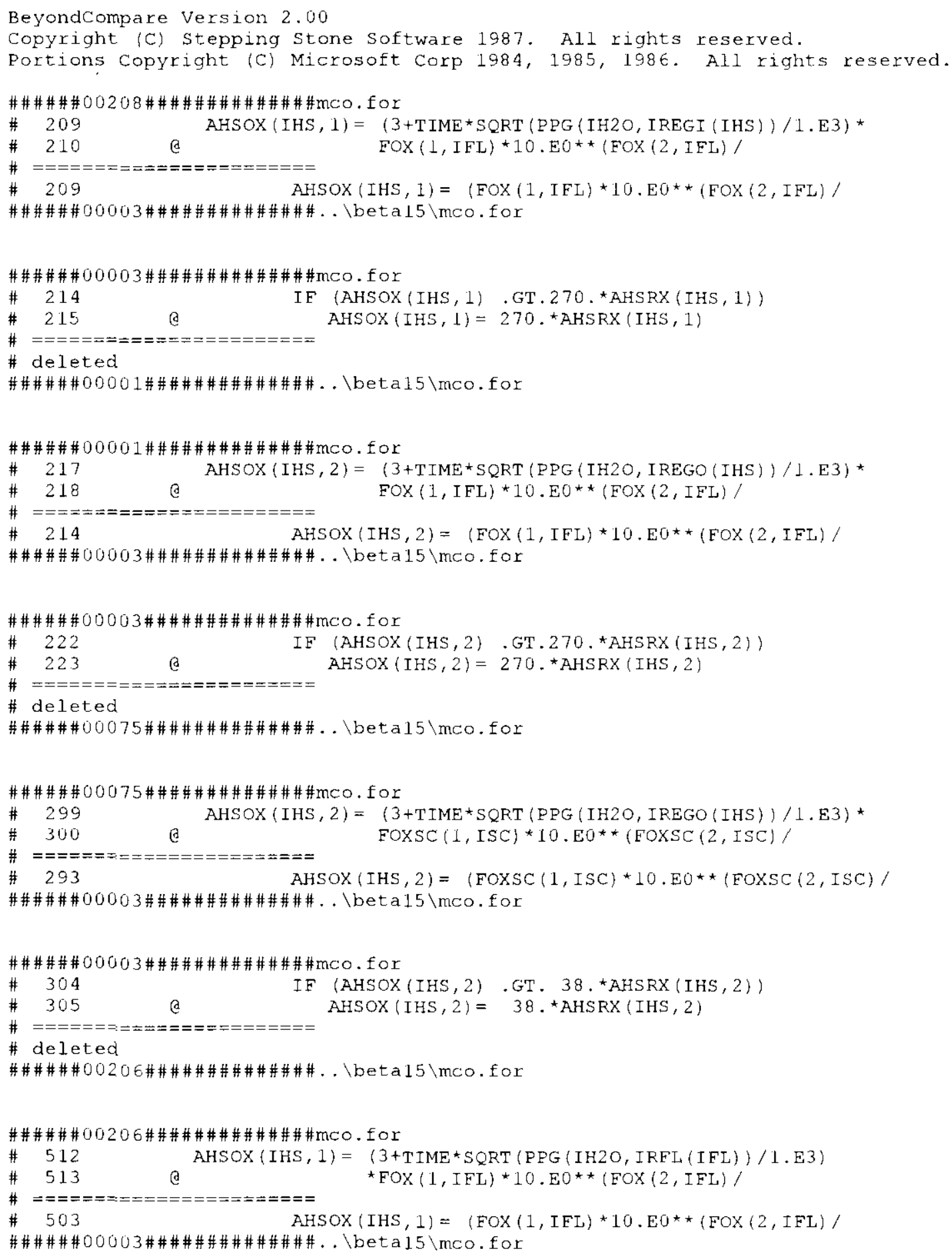




\section{SNF-5698 REV 0}

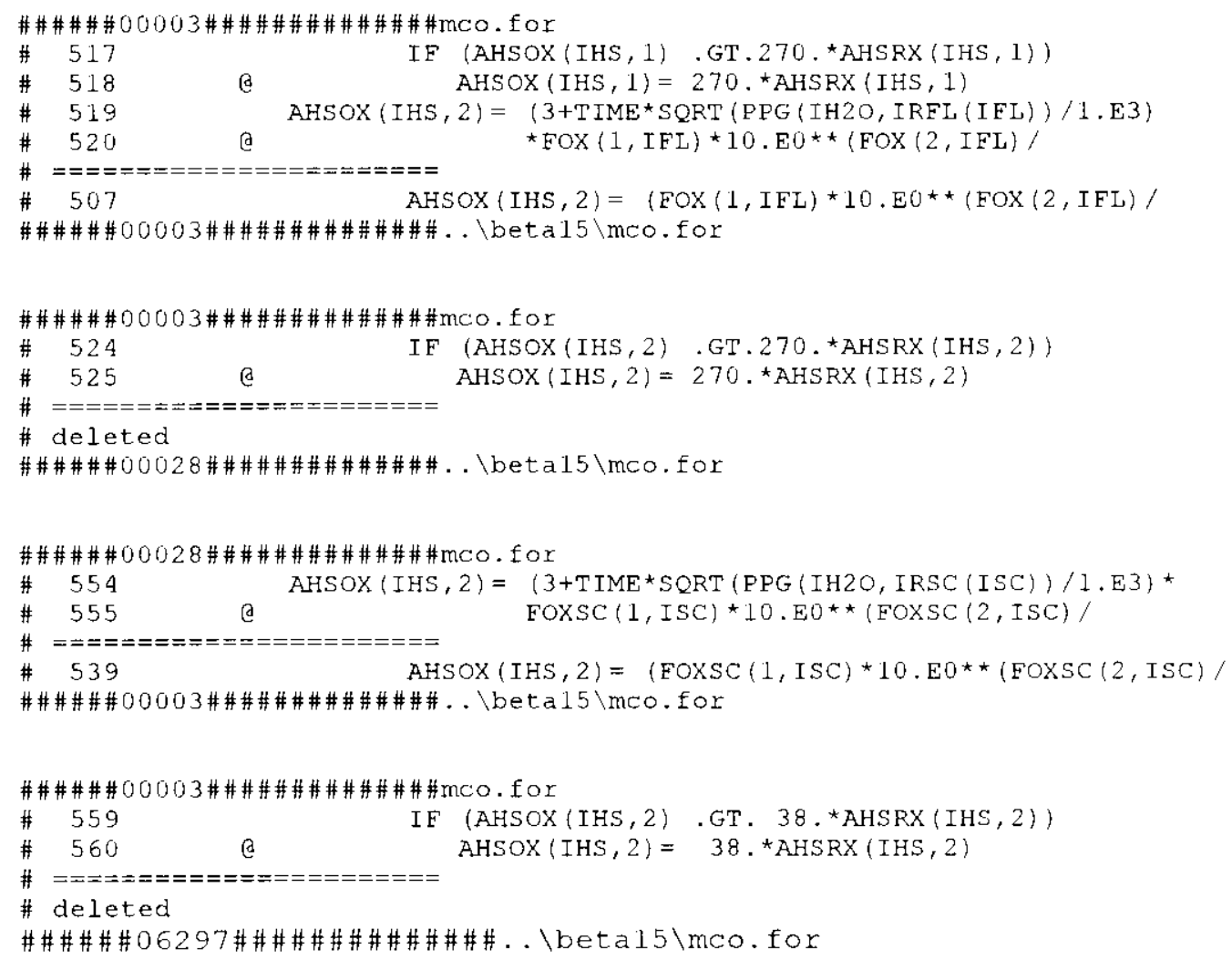


SNF-5698 REV 0

APPENDIX C

PEER REVIEW CHECKLIST 
SNF-5698 REV 0

This page intentionally left blank. 


\section{CHECKLIST FOR PEER REVIEW}

Document Reviewed: SNF-5698, Rev. 0, Comparison of ('alculational Results from Different Spent Nuclear Fuel Crumbling Approaches

Scope of Review: Entire document, excluding 'pepindices

Yes No NA

[ ] [ ] $\mathbb{W}^{*}$ Previous reviews complete and cover analysis, up to scope of this review, with no gaps.

$凶$ [ ] [ ] Problem completely defined.

$凶[$ [ ] ] Accident scenarios developed in a clear and logical manner.

$凶$ [ ] [ ] Necessary assumptions explicitly stated and supported.

[ ] [ ] [ Computer codes and data files documented.

[X] [ ] [ ] Data used in calculations explicitly stated in document.

[X] [ ] [ ] Data checked for consistency with original source information as applicable.

¿] [ ] [ ] Mathematical derivations checked including dimensional consistency of results.

(X] [ ] [ ] Models appropriate and used within range of validity or use outside range of established validity justified.

[X] [ ] [ ] Hand calculations checked for errors. Spreadsheet results should be treated exactly the same as hand calculations.

[ ] [ ] \] Software input correct and consistent with document reviewed.

[ ] [ ] $\$ Software output consistent with input and with results reported in document reviewed.

[ ] [ ] $\$ Limits/criteria/guidelines applied to analysis results are appropriate and referenced. Limits/criteria/guidelines checked against references.

$凶[$ [ ] [ ]

$\bowtie][][]$ Safety margins consistent with good engineering practices.

Conclusions consistent with analytical results and applicable limits.

$\infty[][]$

[ ] [ ] [ [

[ ] $]^{*}$ Results and conclusions address all points required in the problem statement. Format consistent with appropriate NRC Regulatory Guide or other standards Review calculations, comments, and/or notes are attached.

\section{$凶 \mid$ I I I Document approved.}

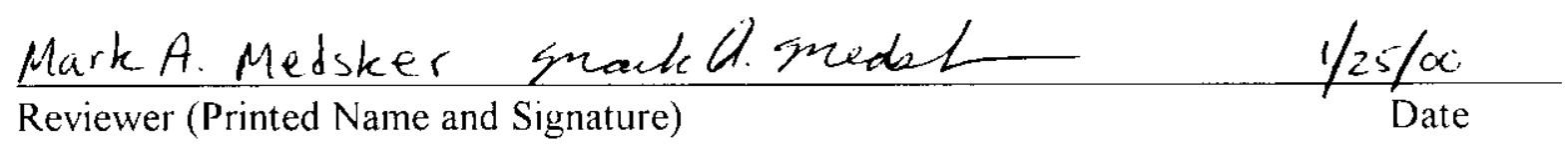

* Any calculations, comments, or notes generated as part of this review should be signed, dated and attached to this checklist. Such material should be labeled and recorded in such a manner as to be intelligible to a technically qualified third party. 


\section{SNF-5698 REV 0}

This page intentionally left blank 